\title{
Safety at work and immigration
}

\section{Cristina Bellés-Obrero ${ }^{1,2}$. Nicolau Martin Bassols²,3 • Judit Vall Castello,}

Received: 30 July 2019 / Accepted: 16 July 2020 / Published online: 27 September 2020

(C) The Author(s) 2020

\begin{abstract}
This paper examines the effect of immigration on workplace safety, an understudied outcome in the literature. We use a novel administrative dataset of the universe of workplace accidents reported in Spain from 2003 to 2015 and follow an instrumental variables (IV) strategy based on the distribution of early migrants across provinces. Our results show that the massive inflow of immigrants between 2003 and 2009 reduced the number of workplace accidents by 10,980 for native workers ( $7 \%$ of the overall reduction during that period). This decline in workplace accidents is driven by Spanish-born workers shifting away from manual occupations to occupations involving more interpersonal interactions. Immigrant flows during the economic crisis (2010-2015) had no impact on natives' workplace safety. The scarcity of jobs during that period may have prevented shifts between occupations. Finally, we find no effects of immigration on the workplace safety of immigrants. These results add a previously unexplored dimension to the immigration debate that should be taken into account when evaluating the costs and benefits of migration flows.
\end{abstract}

Keywords Immigration · Workplace accidents · Safety at work

JEL Classification J61 $\cdot$ J28 $\cdot$ I1

\section{Introduction}

Immigration and its potential consequences continue to be a major concern in many developed countries. The current refugee crisis in the European Union, Brexit, and

Responsible editor: Klaus F. Zimmermann

We are very grateful to the Editor, Klaus F. Zimmermann, and the three anonymous referees for their helpful comments during the revision process. We are also thankful to seminar and workshop participants at the Econometric Society European Winter Meeting, Simposio de la Asociación Española de Economía, 2nd CRC TR 224 Workshop for Young Researchers, and Jornada Immigració i Salut.

Cristina Bellés-Obrero

cbelleso@mail.uni-mannheim.de

Extended author information available on the last page of the article. 
Donald Trump's determination to construct a wall along the Mexico-US border are just examples of how immigration is at the forefront of political debates in developed countries. But what is the source of the immense preoccupation over immigration? There is an unsubstantiated fear that immigration has detrimental effects on many socioeconomic variables, such as criminality, health, and labor outcomes. This paper contributes to the existing literature by examining the effect of immigration inflows and outflows on a new and previously neglected outcome: workplace safety.

Workplace accidents entail massive economic and social costs. They affect not only individuals involved in the accidents, but the society as a whole. According to Takala et al. (2014), 2.3 million individuals died worldwide in 2012 as a result of workplace-related accidents. The implied economic cost of these workplace deaths ranged from 1.8 to $6 \%$ of countries' GDP. The cost of workplace accidents includes not only medical costs and insurance premiums, but also costs related to early retirement, loss of skilled staff, and absenteeism.

In this paper, we focus on Spain, a country that stands in a relatively bad position with respect to its European neighbors regarding workplace safety. Aibar (2006) examines differences in workplace accidents among EU-15 countries for the years 1996 and 2003 and concludes that, in almost all outcomes, Spain was in the lower tail of workplace safety standards. Between 1996 and 2003, Spain had the largest number of workplace accidents that required three or more days of sick leave in order to recover. Moreover, Spain had almost three times the number of workplace accidents in which at least one person dies compared with countries such as Sweden or UK. Therefore, the large personal and economic costs caused by workplace accidents justify the focus on this outcome in Spain.

Most of the literature examining the effects of immigration on labor outcomes has focused on wages and employment of the native population. ${ }^{1}$ There is no strong evidence that immigration has a negative labor market effect on the native population. For instance, Altonji and Card (1991), Borjas (1995), or Friedberg and Hunt (1995) do not find a robust significant effect of immigration on natives' wages or employment. ${ }^{2}$ For Spain, ${ }^{3}$ Amuedo-Dorantes and De la Rica (2008) show that immigration affects the occupational distribution of natives, who shift from occupations with more manual tasks to those with more interactive tasks. Blanes et al. (2011) and Gonzalez and Ortega (2011) examine the effects of immigration on wages and unemployment in Spain over the periods 1995 to 2002 and 2001 to 2006, respectively. They report

\footnotetext{
${ }^{1}$ Theoretically, the direction of this relationship is not clear. On one hand, an inflow of immigrants increases the supply of labor, which could lead to lower wages and higher unemployment rates for the native population. On the other hand, an increase in labor supply could make the economy more competitive, which could be beneficial for the native population in the long run.

${ }^{2}$ On the other hand, Ottaviano and Peri (2005) analyze the impact of immigration on income and find that immigration has a positive effect on natives' income. This relationship may be explained by immigrants not perfectly substituting natives at their workplaces and by immigrants having lower house ownership rates than the natives. Immigration generally leads to an increase in housing prices, which then generates an income transfer from immigrants (lower ownership rates) to natives (higher ownership rates).

${ }^{3}$ Amuedo-Dorantes and De la Rica (2007) were the first to analyze employment and occupational assimilation of recent immigrant waves to the Spanish labor market.
} 
that the immigration inflow does not affect either wages or unemployment among the native population during the period examined. ${ }^{4}$

Examining the effect of immigration on workplace safety fills some gaps in the existing literature. Changes in the labor supply generated by immigration inflows and outflows may affect workplace safety. Firstly, inflows of immigrants could add pressure to the labor supply, inducing Spanish-born workers to accept more precarious working conditions in order to keep their jobs. This could lead to an overall decrease in workplace safety, which could result in an increase of the number of workplace accidents. Secondly, the additional pressure from immigrants on the labor supply could force Spanish-born workers to underreport small workplace accidents due to fear of losing their jobs. This would imply a decrease in the number of reported workplace accidents by Spanish-born workers.

Immigrants tend to be different from the average population in their respective countries of origin and from the native population, as a consequence of self-selection. A large number of authors have examined the phenomenon of self-selection among immigrants (Borjas 1987; Antecol and Bedard 2006; Bertoli 2010; Moraga 2011; Kennedy et al. 2015; Giuntella and Mazzonna 2015; Farré 2016; Giuntella 2017), generally concluding that immigrants tend to be less educated, younger, and healthier with respect to the average native population. These characteristics can affect workplace safety in two different ways. Firstly, immigrants tend to work in unskilled occupations. This is a consequence of having lower education levels with respect to the average native population, as well as suffering from other labor disadvantages. 5 Given their physical demands, unskilled occupations could have a higher injury risk. Thus, an inflow of immigrants that takes over (from native workers) jobs that have a higher injury risk may improve the workplace safety numbers of the native population. Secondly, it seems reasonable to assume that younger and healthier workers will engage in safer attitudes at their workplace compared with older and unhealthier workers. Given this, an inflow of younger and healthier immigrants (with respect to the native population) could improve workplace safety for natives without increasing the number of workplace accidents of immigrants.

Very few studies have explored the effect of immigration on workplace safety. Bauer et al. (1998) examine the interdependence between native and foreign workers in relation to workplace accidents for blue collar occupations in Germany in 1975. They find that $1 \%$ increase in the employment share of foreigners is associated with a $0.4 \%$ decrease of severe accidents of German natives, without affecting immigrants. ${ }^{6}$ Amuedo-Dorantes and Borra (2013) explore the differences in work injury and fatality rates between immigrants and natives during the financial crisis in Spain. They

\footnotetext{
${ }^{4}$ Carrasco et al. (2008), on the other hand, found that the growth in the share of immigrants during the period 1991 to 2001 was negatively correlated with the growth in employment rates and wages. However, their results are small and not robust to different samples and models.

${ }^{5}$ Immigrants have to adapt to the language and social behavior of the host country. Moreover, in many cases, they do not have a strong labor and social network in the host country.

${ }^{6}$ Compared with the paper by Bauer et al. (1998), we find that an inflow of 1000 immigrants decreases the proportion of workplace accidents by 9 for every 100,000 Spanish-born workers (15\%), during the period 2004 to 2009. The difference in size between Bauer et al. (1998) and our paper could be driven by the time period and the sector considered.
} 
find that during the economic downturn, immigrants tended to work in riskier occupations compared with natives. This reduced workplace injury rates of the latter, but not fatality rates. In the context of Germany, Giuntella and Mazzonna (2015) find that immigration reduces the likelihood that residents will report disability. This effect seems to be particularly pronounced for blue-collar occupations and low-skilled individuals. Giuntella et al. (2019) consider the effects of immigration on the allocation of occupational physical burden and work health risk in the UK for the years 20032013. They find that a 10 percentage point increase in the share of immigrants in a local authority reduces the average physical burden of native males by $5 \%$ with respect to the mean. A similar approach to Giuntella et al. (2019) is used for the USA in the paper by Dillender and McInerney (2020) where the authors explore the role of Mexican immigration to the USA on workplace safety for the native population. Their results show that Mexican immigration can explain $26 \%$ of the improvements in occupational risk among natives between 1980 and 2015. It also explains $17 \%$ of the reduction in worker's compensation cash benefits among non-Mexican males in the USA. ${ }^{7}$ The effect of immigration on workplace accidents has not been examined for the USA or the UK.

We contribute to this scarce literature in several dimensions. Firstly, we use a novel administrative database that includes the universe of workplace accidents that were registered in Spain from 2003 to 2015. This database allows us to analyze in detail the mechanisms behind the effect of immigration on workplace accidents, as we have information about the gender, age, and nationality of the worker that suffered the accident, the occupation that he/she was performing at the time of the accident, and the level of severity of the accident. Secondly, we examine this effect for both Spanish-born and immigrant workers. Thirdly, we focus on Spain, a country that stands in a relatively bad position with respect to its European neighbors in terms of workplace safety (Aibar 2006). In addition, Spain has been experiencing dramatic changes in immigration flows in recent years. These two facts make Spain very suitable to study our research question. Fourthly, during the period studied, Spain experienced both a massive inflow (2003-2009) and outflow (2010-2015) of immigrants, which gives us the opportunity to study the symmetry of the effects. ${ }^{8}$ Finally, we provide causal estimates. As the actual changes of immigrant population might be endogenous, and correlated with shocks in the labor market, we follow the instrumental variable approach developed by Altonji and Card (1991) and Card (2001).

\footnotetext{
${ }^{7}$ A recent working paper by Alacevich and Nicodemo (2019) uses Italian data and finds that a 10 percentage point inflow of foreign-born residents is associated with reductions in the injury rate for the native population of $8.5 \%$ of its mean.

${ }^{8}$ Another reason why we divided the data into two periods is the economic crisis that hit Spain hard, especially after 2009. The unemployment rate went from $10 \%$ in the first quarter of 2008 to $18 \%$ in the first quarter of 2009 and up to a peak value of $27 \%$ in the first quarter of 2013. Thus, the strong reduction in employment and labor market opportunities from the onset of the 2008 recession coupled with reductions in social assistance benefits introduced by the government to reduce the public deficit (cuts in unemployment benefits, health care, etc.) had a massive impact on immigration flows in Spain. In 2002, an inflow of 742,000 immigrants was estimated in Spain. This rose to 777,000 in 2007. After the 2008 recession, this trend stopped drastically. In 2008, the inflow of immigrants in Spain was of 599,074 immigrants and in 2014 of 291,041 immigrants (Alonso et al. 2015).
} 
Immigrants' location decisions are strongly influenced by earlier settlement patterns of individuals of the same country of origin who migrated before them. Then, we use immigrant clusters during the 1980s in Spain's provinces to distribute the current national inflow of immigrants from each country across the different provinces in Spain. This way, we are able to reduce the endogeneity bias.

For the entire time period, we find that an inflow of 1000 immigrants decreases the incidence of workplace accidents by 4.2 for every 100,000 Spanish-born workers. This effect is entirely driven by the period 2004 to 2009 . Our results show that an inflow of 1000 immigrants decreased the proportion of workplace accidents by 9 for every 100,000 Spanish-born workers. Performing a simple back of the envelope calculation indicates that a drop in the number of working accidents suffered by the native population amounting to 10,890 during the period 2004 to 2009 may be attributed to the inflow of immigrants during this period in Spain. This constitutes a $7 \%$ of the overall decrease in the number of workplace accidents during that time period. This effect is larger for men than women. An inflow of 1000 immigrants reduced the proportion of workplace accidents by 12 for every 100,000 workers for men and by 5 for women. We find a reduction in both mild and severe accidents, supporting the idea that reporting biases are not an important concern, at least for natives during this time period. Finally, the reduction of workplace accidents is stronger in the service sector, where immigrants are overrepresented.

Similar to the previous literature, we find evidence that immigration influences the type of occupations in which natives are employed during the period 2004 to 2009. While immigrant inflows tend to reduce the employment rate of natives in occupations such as low or medium rank officers in the armed forces, workers in agricultural, farming and fishing sectors, in the extractive industry, or in domestic work, we find that immigration inflows increase employment of natives as technicians and associate professionals, managers with less than 10 employees, or project managers and team leaders. Using the $\mathrm{O} *$ NET classification, ${ }^{9}$ we give suggestive evidence that native workers reallocate from jobs which entail a higher physical burden (i.e., jobs with more exposure to hazardous equipment, minor burns, cuts, or bites, or that require protective or safety equipment) to jobs that require more human interactions (i.e., jobs that require public speaking, use of letters and memos, face-to-face discussions, work in groups or teams, interaction with external customers or coordination or supervision). Given this, the reduction in the number of workplace accidents that we find could be driven by the reallocation of native workers toward jobs that have probably lower injury risks. These results are consistent with those of Giuntella et al. (2019) and Dillender and McInerney (2020) for other countries.

For the period 2010 to 2015, we find that immigration flows have a small positive effect on workplace accidents. However, this effect is quite sensitive to the different specifications and robustness checks. We also show that, during that time period, immigration influenced much less the type of occupations in which natives

\footnotetext{
${ }^{9}$ The Occupational Information Network $\left(\mathrm{O}^{*} \mathrm{NET}\right)$ is developed under the sponsorship of the U.S. Department of Labor/Employment and Training Administration and contains a rich set of variables that describe work and worker characteristics, including skill requirements.
} 
are employed. In particular, we only observe a decrease in the probability that native workers are employed as technicians and an increase in the probability of being employed as a professional, operator, or in the construction sector or in other elementary occupations. We believe that the economic crisis of 2008, which hit Spain particularly hard, could be behind the differences between the two time periods. In particular, the scarcity of jobs during that period could have prevented a larger shift between occupations.

Finally, we do not find any significant effect of immigration on workplace safety of immigrants. Previous literature has pointed out that immigrants tend to be less educated, younger, and healthier than the average population. In addition, the downward occupational mobility that immigrants experience after their arrival to Spain makes them, in some cases, overqualified for the jobs they perform. This null effect among immigrants, then, goes in line with younger, healthier, and overqualified immigrant workers engaging in safer attitudes at the workplace compared with native workers. If this is true, we could expect the inflow of immigrants to improve workplace safety for natives without increasing the number of workplace accidents of immigrants. Yet, this explanation is speculative given that we are not able to explore this mechanism in this paper, due to data limitations.

The remainder of the paper is organized as follow. Section 2 explains the suitability of having Spain as the focus of the study. Section 3 describes the data sources and introduces the empirical strategy. Section 4 presents the results and Section 5 concludes.

\section{Why Spain?}

In the past years, Spain has experienced large inflows and outflows of immigrants. More precisely, the share of immigrants with respect to the total population in Spain increased from $8.07 \%$ in 2003 to $15.78 \%$ in 2010 (Spanish National Institute of Statistics). However from 2010, this increasing trend reversed and the share of immigrants fell to $13.54 \%$ in 2015 . Figure 1 illustrates how these flows have fluctuated over time. The strong inflow of immigrants until 2009 can be explained by Spain's strong economic growth during that time period (partly led by a housing bubble), while the change in trend was due to the onset of the great recession of 2008. This scenario offers an ideal opportunity to study the symmetry of the effects of immigration inflows with respect to its outflows.

Immigration inflows and outflows have been quite heterogeneous across the different regions of Spain. This is probably a result of huge cultural and socioeconomic differences among the subregions of Spain. Figure 2 represents the mean annual change in the share of immigrants (aged 25-54) for the 52 Spanish provinces. The first graph considers changes from the years 2003 to 2009, while the second graph covers the years 2010 to 2015 . We observe a large heterogeneity among the 52 provinces. For instance, from 2003 to 2009, the share of immigrants grew more than $1.5 \%$ every year on average in Almería, La Rioja, Tarragona and Girona. For the 
same time period, there were provinces that experienced an annual growth rate of at most $0.1 \% .^{10}$ The period from 2009 to 2015 also saw variations across provinces with positive growth for some provinces and negative growth for others.

The important changes in immigration flows in the past few years and the heterogeneity of these changes across provinces make Spain an ideal scenario to examine the effects of immigration flows on workplace accidents.

\section{Data and empirical straregy}

\subsection{Data sources}

For our analyses we use three different data sources: the Register of Workplace Accidents, the Spanish Labor Force Survey, and the Census of 1991.

The Register of Workplace Accidents is a newly released dataset that contains detailed information on non- fatal and fatal workplace accidents that were registered in Spain from 2003 to 2015. This database is collected by the Spanish Social Security Administration and includes personal data of the injured worker (gender, month and year of birth, nationality), information about the job that he/she was performing at the time of the accident, and the date, place, level of severity, and consequences of the accident. The data provides a total of 9,562,105 workplace accidents for the years 2003 to 2015 . We restrict the analysis to the population aged 25 to $54(7,310,660$ observations) as this constitutes the bulk of the working-age population and minimizes the age composition effects. ${ }^{11}$ The number of workplace accidents for natives and immigrants are considered separately for our study. For our main specification, we collapse the individual data at the level of year, province, and gender $\left[W A(t)_{r g}\right] .{ }^{12}$ This way we generate a panel data of workplace accidents in each province and gender over time. For our heterogeneity analysis, we further collapse the individual data at the level of year, province, gender, and economic activity $\left[W A(t)_{\text {rga }}\right],{ }^{13}$ or level of severity $\left[W A(t)_{\text {rgs }}\right] .^{14}$

Note that this database only contains reported workplace accidents. We believe that biases in reporting should be lower for fatal accidents, so examining fatal and non-fatal accident separately will be useful to asses the importance of this bias. There is some anecdotal evidence that immigrants are both less likely to report workplace accidents while, at the same time, those that do report the accident are less likely to be granted sickness leave when compared to the native population

\footnotetext{
${ }^{10}$ Palencia, Jaen, Badajoz, or Melilla.

${ }^{11}$ Our results are robust if we re-estimate all models for the population aged 25 to 45 , and 25 to 65 . In the GLO working paper (that can be found in https://ideas.repec.org/p/zbw/glodps/565.html), Table A11 shows our main results estimated for the population aged 25 to 45 , while Table A12 reports our main results for individuals aged 25 to 65 .

${ }^{12}$ The collapsed data will have 1352 observations ( 13 years*52 provinces $* 2$ sex).

${ }^{13}$ The collapsed data will have 5408 observations (13 years*52 provinces $* 2$ sex $* 4$ economic activities).

${ }^{14}$ The collapsed data will have 2704 observations (13 years*52 provinces*2 sex*2 levels of severity).
} 
(Instituto Sindical de Trabajo and Ambiente y Salud 2006). ${ }^{15}$ However, according to the report, these differences in reporting behavior between immigrants and the native population seem small and very persistent over time. Unfortunately, there is no other panel data source available that can provide a more quantitative and in-depth analysis of these trends. Thus, we should keep in mind when interpreting our results that these small underreporting differences may slightly bias downwards our results, specially for the immigration group.

The Spanish Labor Force Survey (LFS) is a continuous quarterly survey with information related to the labor force status of the population living in Spain. We use this database from 2003 to 2015 (8,872,258 observations in total). Following Gonzalez and Ortega (2011), we also take this database as appropriate to capture demographics of the foreign-born and the Spanish-born populations. For one, it is a reliable, large-sample, and up-to-date database. For another, the LFS uses a sampling design based on the local population registry data. Therefore, this database not only is representative at the regional level, but also includes all individuals living in Spain, independently of their nationality and their legal status. ${ }^{16}$ We apply weights to the sample as provided by the Spanish Institute of Statistics. Among others, the LFS contains information regarding the province of residence, educational level, age, gender, country of birth, employment status, and economic activity of those employed. We restrict the sample to individuals between 25 and 54 years of age. As in Gonzalez and Ortega (2011), we construct three educational level categories: high school dropouts, ${ }^{17}$ high school graduates,${ }^{18}$ and tertiary education graduates. ${ }^{19}$

We use the LFS to come up with several indicators used for the instrument and the dependent variables. First, we construct the annual inflow of migrants between the years 2003 to 2015 that we will use as part of our instrument. In order to do this, we restrict the LFS to individuals with non-Spanish nationalities and we collapse the data by year, country of origin, ${ }^{20}$ gender, and educational level $\left[M(t)_{g e c}\right] \cdot{ }^{21}$ We also use the LFS to calculate the number of Spanish and foreign-born individuals employed as a dependent variable. We first keep those individuals that are employed, and then collapse the data at the year, gender, province, and educational level $\left[E(t)_{\text {rge }}\right] .{ }^{22}$

The third database is the Census of 1991, which surveys a representative sample of 5\% of the population that lived in Spain in 1991 and collects information on

\footnotetext{
${ }^{15}$ This information is taken from a report carried out by the Spanish Ministry of Employment and Social Affairs in which several immigrants were surveyed at the individual level and this was combined with a number of focus groups.

${ }^{16}$ Then, this data measures inflows of immigrants, both legal or illegal.

${ }^{17}$ High school dropouts include all individuals that at most completed the first stage of secondary education, or vocational studies that only required the first stage of secondary education as a prerequisite.

${ }^{18}$ We consider as high school graduates those individuals that obtained a high school degree or those with middle or advanced-level professional training.

${ }^{19}$ Those with a university degree or beyond.

${ }^{20}$ We generate 17 different countries or areas of origin: France, Italy, Portugal, UK, Germany, Other EU12, other Europe, Morocco, other Africa, the USA, Cuba, Argentina, Venezuela, Mexico, or Canada, other Central America and Caribbean, other South America, and Asia and Oceania.

${ }^{21}$ The collapsed data will have 1224 observations (13 years*2 sex*3 levels of education*17 countries).

${ }^{22}$ The collapsed data will have 4056 observations ( 13 years*2 sex*52 provinces $* 3$ levels of education).
} 
individuals' characteristics, households, buildings, and dwellings. The raw data contains information on 3,894,525 individuals. We first restrict our sample to all those individuals aged 25-54 (1,523,483 obs.) and foreign (22,098 obs.). We use this database to calculate our instrument, determining the distribution of immigrants across the Spanish provinces in 1991 . We do this by collapsing the individual data at the country and province levels $\left[M(1991)_{r c}\right]$, and then dividing it by the individual data collapsed at the country level $\left[M(1991)_{c}\right] .^{23}$

\subsection{Descriptive evidence}

In Fig. 3, we can observe the evolution of the number of workplace accidents and the total number of individuals employed for both natives (top graph) and immigrants (bottom graph). For Spanish-born individuals, the total number of employed individuals increased from 2003 to 2009, as we expected, due to the economic boom that Spain was experiencing during these years. At the same time, the number of workplace accidents experienced by Spanish-born workers did not increase proportionately, remaining quite flat during 2004 and 2009 at around 650,000 accidents a year. During the same period, the number of immigrants employed also increased substantially however, in contrast to the native population; the number of workplace accidents for these individuals also increased significantly. After 2009, with the onset of the recession, we observe a decrease in the number of individuals employed for both the native and immigrant populations. But the decrease in the number of workplace accidents was larger for the immigrant population than for the native one.

Table 1 reports the descriptive statistics on the percentage of workplace accidents and the total number of workers collapsed at the province, year, and gender level (economic activity or level of severity). Note that there are more or less the same percentage of workplace accidents involving immigrants as natives. On average, before 2009 there are 4.37 workplace accidents for every 100 Spanish-born workers, and 4.69 accidents per 100 immigrant workers per year and province. After 2009, the incidence of workplace accident is lower for both natives and immigrants (2.89 accidents per Spanish-born worker and 2.36 accidents per immigrant worker, on average). We can also observe that workplace accidents are more common for men than women, although this difference becomes smaller after 2009. As expected, before 2009, the construction sector takes a higher percentage of workplace accidents per worker (for both immigrants and natives). After 2009, immigrants working in the agriculture sector have the higher share of workplace accidents. Finally, it is important to note that the majority of workplace accidents have been classified as mild in nature.

\subsection{Empirical strategy}

In order to examine the effects of changes in immigration on workplace accidents of the native and foreign-born population, our main outcome variable will be the annual change in the number of workplace accidents per employed individual. In order to

\footnotetext{
${ }^{23}$ The collapsed data will have 884 observations (17 countries*52 provinces).
} 
construct the dependent variable, we first divide the number of workplace accidents of Spanish-born or foreign-born individuals of gender $g$ living in province $r$ by the number of Spanish-born or foreign-born employed individuals of gender $g$ living in province $r$ each year $t\left[\frac{W A(t)_{r g}}{E(t)_{r g}}\right]$. Then, we calculate the annual change of the number of workplace accidents per worker $\left[\frac{W A(t)_{r g}}{E(t)_{r g}}-\frac{W A(t-1)_{r g}}{E(t-1)_{r g}}\right]$. To facilitate the interpretation, we will multiply the dependent variable by 100,000 .

On the other hand, our main regressor is the annual change in the number of the immigrant population of a certain gender $g$ and education $e$ in a province $r$. This regressor is constructed by subtracting the number of immigrants of a certain gender, and educational level living in a specific province in year $t\left[M(t)_{\text {rge }}\right]$ from the number of immigrants of a certain gender and educational level living in that same province the year before $t-1\left[M(t-1)_{\text {rge }}\right]$. Thus, our regressor could be expressed in the following way: $\left[M(t)_{\text {rge }}-M(t-1)_{\text {rge }}\right]{ }^{24}$ To ease interpretation, we divide this migration flow by 1000 .

We then estimate a regression of the following form:

$$
\begin{aligned}
\left(\frac{W A(t)_{r g}}{E(t)_{r g}}-\frac{W A(t-1)_{r g}}{E(t-1)_{r g}}\right) * 100,000=\alpha & +\beta \frac{\left(M(t)_{r g e}-M(t-1)_{r g e}\right)}{1,000} \\
& +\delta_{t}+\alpha_{r}+\mu_{g}+\gamma_{e}+\epsilon_{\text {trge }}
\end{aligned}
$$

The main coefficient of interest $\beta$ is interpreted as the effect of an inflow of 1000 immigrant of gender $g$ and skill group $e$ in province $r$ on the number of workplace accidents of individuals of that gender $g$ in the province $r$ and year $t$ per 100,000 workers. In addition, our specification includes year, province, gender, and education fixed effects $\left(\delta_{t}, \alpha_{r}, \mu_{g}\right.$, and $\gamma_{e}$, respectively). We estimate all regressions with standard errors clustered at the province level (52 provinces) and using weights. ${ }^{25}$

The inclusion of fixed effects addresses the issue of unobserved heterogeneity across time, provinces, gender, and skill groups. However, our previous specification will still be affected by the endogeneity of immigrants' location choices. For instance, immigrant inflows will most likely occur in provinces with high economic growth, low unemployment, and/or more jobs with lower injury risk (the other way around with immigration outflows). To solve this problem, we adopt an instrumental variable approach (the shift-share instrument or Bartik instrument) following Altonji and Card (1991), Card (2001), and Gonzalez and Ortega (2011).

The objective of this instrument is to disentangle the exogenous part in immigration inflows and outflows from its endogenous part. In other words, we want a variable that is correlated with the percentage change of the immigrant population, but is orthogonal to the local specific shocks and trends in the labor market conditions. This approach exploits the observation that changes in immigration are tightly

\footnotetext{
${ }^{24}$ Our results are robust in sign and significance level if we divide the migration flows and the instrument by the population in each province, gender, and educational cell in the period $t-1$. Table 14 reports the main results using this alternative specification.

${ }^{25}$ For our first stage and employment regressions, we use as weight the Spanish population of specific gender and educational level living in each province in $t-1$. For our workplace safety regressions, we use as weight the Spanish/immigrant employed population of specific gender living in each province.
} 
linked with migrant networks. Immigrants tend to move to areas where big groups of immigrants from their same country of origin are already established. As discussed in the previous section, we use the Census (1991) to determine the cluster of immigrants of different countries across the different Spanish provinces in 1991.

Using this data, we calculate the share of all immigrants born in country $c$ living in province $r$ in $1991\left[\Pi_{r c}\right] .{ }^{26} \mathrm{Next}$, we compute country-wide changes over time for the number of immigrants from country $c$, with gender $g$ and educational level $e,\left[M(t)_{g e c}^{e s p}-M(t-1)_{g e c}^{e s p}\right]$. Then we build the imputed change of immigrants over time from country $c$, gender $g$, and educational level $e$ multiplying the country-wide changes with the share of immigrants in each province in 1991. Finally, we obtain our instrument by summing up the previous indicator over all countries:

$$
Z(t)_{\text {rge }}=\sum_{c=1}^{C} Z(t)_{\text {rgec }}=\sum_{c=1}^{C} \Pi_{r c}\left(M(t)_{\text {gec }}^{\text {esp }}-M(t-1)_{\text {gec }}^{\text {esp }}\right)
$$

This instrument should reflect the exogenous annual inflows and outflows of immigrants in Spain between 2003 and 2015.

\subsection{Identification assumptions}

For our IV approach to derive causal estimates, we need two identification assumptions to hold: the exclusion restriction and instrument relevance.

\subsubsection{Exclusion restriction}

The exclusion restriction requires that the motivations for most immigrants to migrate to the different Spanish provinces in the 1980s should be uncorrelated with our outcome of interest (workplace accidents) during the period 2003 to 2015. Although this statement cannot be formally proved, we provide evidence to support that this identification assumption holds.

First, we use a lag of more than 10 years between the measurement of our instrument and our outcomes of interest, which is considered sufficiently long for the assumption to hold. Secondly, we are able to present suggestive evidence that the location patterns of early immigrant groups are uncorrelated with the more recent changes in regional labor market conditions. Figure 4 shows the distribution of South American and African immigrants across the different provinces of Spain in the Census of 1991. We see that South American and African immigrants had very distinct geographic distributions in 1991. If we ignore Madrid and Barcelona, that had important immigrant clusters from all countries, African immigrants tended to have more presence in the south-eastern coast. This could be explained by the geographic proximity to their countries of origin. On the other hand, South Americans were clustered in the northwest provinces and in the Canary Islands. In the early 20th century, there was considerable emigration to South America from these regions. It is likely

\footnotetext{
${ }^{26}$ Our results are robust to the use of gender- and education-specific baseline shares in the instrument $\left[\Pi_{\text {rgec }}\right]$.
} 
that part of the South American immigrant inflows into these regions during the 1980s was mostly composed by descendants or relatives of these Spanish emigrants. These two distinct patterns support the exogeneity of the instrument, suggesting that non-economic reasons largely determined the location choices of early immigrant settlements within Spain.

Jaeger et al. (2018) pointed out that the exclusion restriction of the shift-share instrument will be violated in the presence of strong serial correlation of immigrant flows. However, this is a very unlikely problem in our setting. The immigration pattern in Spain has changed substantially over the years, leading to a smaller correlation in the number of immigrants by country of origin compared with the USA. ${ }^{27}$ In Fig. 5, we show the correlation in the share of immigrants coming from a certain country living in a particular province in Spain in 1991 with 2006 (top graph), and later with 2015 (bottom graph). We do not observe a strong correlation between these years ${ }^{28}$ indicating that the composition of immigrants has changed over time in Spain. Moreover, Fig. 6 reports the composition of immigrants in Spain by country of origin at four points in time. We see that the country of origin composition of migrants has changed substantially across time. The period from 1998 to 2003 saw an increase in the percentage of immigrants coming from South America. However, this percentage has declined since then. On the other hand, the number of immigrants with European origins has increased since 2003. Later, in Section 4.4, we show the results from adopting the "multiple instrumentation" procedure suggested by Jaeger et al. (2018) to check if our main results are robust to the inclusion of lagged immigrant inflows.

\subsubsection{Instrument relevance}

To fulfill the second requirement that our instrument is relevant, that is, our instrument should be able to predict actual changes in the migration flows, we analyze whether the instrument is correlated with the actual changes in the immigrant population. This will be our first-stage regression. The dependent variable will be the change over time in the actual number of the immigrant population of a certain gender $g$ and educational level $e$ taking place in province $r\left[M(t)_{r g e}-M(t-1)_{r g e}\right]$. The instrument is the main regressor. Thus, we estimate the following regression:

$$
\frac{M(t)_{\text {rge }}-M(t-1)_{\text {rge }}}{1,000}=\alpha+\beta \frac{Z(t)_{\text {rge }}}{1,000}+\delta_{t}+\alpha_{r}+\mu_{g}+\gamma_{e}+\epsilon_{\text {trge }}
$$

Table 2 reports the OLS estimates of the first-stage regressions for the entire period, as well as, two different periods: 2004-2009 and 2010-2015. As we mentioned at the beginning of the paper, Spain experienced a massive inflow of immigrants from 2003 to 2009 due to the strong economic expansion during this

\footnotetext{
${ }^{27}$ This was already pointed out by Jaeger et al. (2018): "the prospects to satisfy the exclusion restriction may be better in settings in which the first-stage link is weaker because immigrant inflows have been less stable over time, as is the case in many European countries."

${ }^{28}$ Under the presence of strong serial correlation, we will observe all the dots over the 45 degree line.
} 
period. However, this trend reversed with the onset of the recession in 2008, and Spain began to experience some outflows of immigrants (particularly pronounced in certain regions). As we expect, differential effects between inflows and outflows of immigrants on workplace safety; for the rest of the paper, we will analyze these two periods separately. ${ }^{29}$

Across all the samples, we observe that the coefficient of our instrument is highly significant and close to one, as expected, based on the definition of the instrument. More importantly, the F-statistics of the excluded instrument is high (greater than 10) for all the subgroups, indicating that the instrument is relevant and strong.

\section{Results}

\subsection{Baseline results}

In this section, we examine the effects of the imputed changes in the number of the immigrant population on the proportion of workplace accidents for native and foreign-born workers. In column 1 of Table 3, we observe this relationship for the native population during the period 2004 to 2015 . The OLS specification in the top panel of the table already shows a negative coefficient, though smaller than the IV estimate found at the bottom panel of the table. The OLS estimates, for natives, are upwardly biased due to the suspected endogeneity of migrants' location choices. ${ }^{30}$ The IV estimates indicate that, for the period 2004 to 2015, an inflow of 1000 immigrants of a certain gender and educational level in a province decreases the number of workplace accidents by 4.25 for every 100,000 Spanish-born workers.

This negative and significant effect is entirely driven by the period 2004 to 2009 . During that period, an inflow of 1000 immigrants of a certain gender and educational level in a province decreases the number of workplace accidents by 8.86 for every 100,000 Spanish-born workers. Performing a simple back of the envelope calculation shows that working accidents were reduced by 10,890 for native workers during the period 2004 to 2009 (as there is an average of 40,209 workers of each gender and education level in each province and the mean inflow of immigrants is 1616 for each gender and educational level in each province). ${ }^{31}$ We also analyze the effects

\footnotetext{
${ }^{29}$ Figure 9, in the Appendix, reports the IV estimates of the effect of immigration inflows on workplace accidents for native workers considering different time periods.

${ }^{30}$ This positive bias is consistent with, for instance, immigrants migrating more to provinces where the number of job openings with low probability of injury is increasing. These provinces will experience a stronger labor supply shock, reducing the probability of natives obtaining a job with low risk of injury. For natives, then, the omitted variable (change in safe jobs) will be positively correlated with migration flows and workplace accidents.

${ }^{31}$ Our estimates show a reduction of working accidents by 0.0009 (for each 100,000 workers) when 1 immigrant enters. As there is a mean of 40,209 workers in each province (of each gender and educational level and year) each immigrant reduces accidents by $0.0036(0.00000009 * 40209)$ for each gender, education, year, and province. As, on average, there is an inflow of 1,616 immigrants (for each province, gender, education, and year) accidents are reduced by 5.8 (1616*0.0036) (for each gender, education, province, and year). Finally, as there are 52 provinces, 2 genders, and 6 years and 3 educational levels, accidents are reduced by 10,890 for native workers for the entire period $(1872 * 5.8)$.
} 
by gender. In columns 3 and 4 of Table 3, we observe that this relationship is larger for men than for women. An inflow of 1000 immigrants in a province decreases the number of workplace accidents by 12.7 for men and 4.9 for women (for every 100,000 workers).

In columns 5, 6, and 7 of Table 3, we explore the same effects for the years 2010 to 2015. We find that immigration flows have a small positive effect on workplace accidents for natives for that period. Yet, this small effect is very sensitive to the specification chosen. For instance, this effect is no longer significant if we consider the period 2011-2015 instead (Fig. 9); we estimate this effect for the population aged 25 to 45 , or the data is collapse by year and province or by year, province, and level of severity (Tables 15 and 17). We also do not find any significant effect for any of the subgroups (men or women) for this period.

Table 4 shows the effect of changes in the number of immigrants on the change in the proportion of workplace accidents for foreign-born workers. ${ }^{32}$ This table indicates that neither inflows nor outflows of immigrants have any significant effects on their workplace safety.

Figure 9, in the Appendix, reports the IV estimates considering different time periods. We can observe that the result is stable around -9 for the periods 2004-2006, 2004-2007, 2004-2008, 2004-2009, and 2004-2010. Adding more years after 2010 to the period analyzed significantly reduces the magnitude of the effect, but the result continues to be negative and significant. If we consider only the last years available, the effect is always close to zero and not significant, except for the periods 20082015, 2009-2015, and 2010-2015, where the immigrant inflows increase workplace accidents for natives. This graph indicates that the negative effect of immigration on workplace safety that we find in Table 3 for the second period is very sensitive to the time period chosen.

As we explained before, in constructing the instrument, we collapsed the data at four levels: year $(t)$, province $(r)$, educational level $(e)$, and gender $(g)$. To ensure that our results are not driven by the level of aggregation, Table 15 shows the results on the effect of immigrant inflows on the number of workplace accidents of native workers when we collapse the data only at the year and province level. An inflow of 1000 immigrants in a province decreases the number of workplace accidents by 2.26 for every 100,000 Spanish-born workers during the period 2004-2009. However, we do not observe any impact during the period 2010 to 2015. In Table 16, when we collapse the data only at the year, province, and gender level, we find the same pattern as in Table 3. Therefore, we can conclude that our results are not driven by the level of aggregation of the data.

\footnotetext{
${ }^{32}$ Note that, for immigrants, the OLS bias is negative. This negative bias is consistent with, for instance, foreigners migrating more to provinces where the number of job openings with low probability of injury is increasing. Then, immigrants will have a higher probability of being employed in safer jobs. For immigrants, then, the omitted variable (change in safe jobs) will be positive correlated with migration flows but negatively correlated with workplace accidents.
} 


\subsection{Heterogeneous effects}

In this section, we analyze the impact of immigration on workplace accidents depending on the level of severity of the accident. The increase in competition for a job due to immigration pressures could decrease workplace absences due to mild accidents. The fear of losing one's job due to absenteeism might induce native workers not to report accidents that are not considered severe. Occurrence of severe accidents would be more difficult to hide or ignore, however, and workers are compelled to declare them. As the Register of Workplace Accidents distinguishes between mild and severe working accidents, we also perform the baseline analysis differentiating between these two types of accidents. Table 5 shows a significant effect for both mild and severe accidents for the period 2004 to 2009, though the reduction is larger for mild accidents. ${ }^{33}$ Finding significant effects on the incidence of severe accidents suggests that reporting biases are not a very important concern, at least for natives during this time period. ${ }^{34}$

Some types of jobs may involve higher accident rates than others. We expect immigrant flows to have a specific influence on workplace safety for the different economic sectors. In Table 6, we examine whether immigration flows affect workplace accidents of natives differently by economic sector. We divide our sample into four sectors: agriculture, industry, construction, and services. The IV estimates in Table 6 indicate that changes in immigrant flows have significant effects on workplace accidents only for jobs in the services sector between 2004 and 2009. An inflow of 1000 immigrants of a certain gender and educational level in a province decreases the number of workplace accidents by 8.3 in the service sector (for every 100,000 native workers). ${ }^{35}$ Immigrants are overrepresented in the service sector. In particular, during 2003 to 2015 , around $70 \%$ of all immigrants were employed in the service sector, and this percentage is increasing with the level of education of the immigrant. ${ }^{36}$

Finally, we analyze if the positive effect of immigrants on workplace safety of natives differs by the skill level of the immigrant population. However, most immigrants working in Spain have low qualified occupations, independently of their education level. Using the Spanish Labor Force Survey from 2003 to 2015, Fig. 10 shows that immigrants in Spain, independently of their level of education, are overrepresented in elementary jobs, especially as domestic employees, in construction, services, and in other type of elementary occupations. In addition, Stanek and Ramos (2013) use data of the Spanish National Immigrant Survey of 2007 and estimate that around $50 \%$ of immigrants have experienced downward occupational mobility after

\footnotetext{
${ }^{33}$ Table 17 in the Appendix shows that the results by the level of severity of the workplace accident are robust when we collapse the data only at the year, province, and level of severity of the accident.

${ }^{34} \mathrm{We}$ also find a small positive effect of immigration flows over mild workplace accidents of natives for the period 2010-2015. However, as we can observe in Tables 17 and Table 13, this effect is not robust.

${ }^{35}$ Table 18 in the Appendix shows that the results are robust when we collapse the data only at the year, province, and economic activity.

${ }^{36}$ We also find a positive effect of immigration flows over workplace accidents of natives in the construction sector for the period 2010-2015. However, as we can observe in Table 13, this effect is not robust.
} 
their arrival in Spain. Less than 13\% of immigrants experienced upward mobility and only around $37 \%$ found jobs adequate to their pre-migration occupational status. In Table A5 of the GLO working paper, we analyze the effect of changes in the number of immigrants based on the different education levels on the change in the proportion of workplace accidents for the native population. We find the largest effects for immigrants with tertiary education, which is consistent with these immigrants being more likely to experience downgrading and being overqualified for the occupations they develop in Spain.

In Tables A6, A7, and A8 of the GLO working paper, we perform the same heterogeneity analysis for foreign-born workers. Consistent with our main results, we do not find any effect on workplace safety by severity of the accident, education level, or economic sector for immigrants.

\subsection{Possible mechanisms}

Workplace accidents of natives The change in workplace safety of native workers in the period 2004 to 2009 may have occurred through different channels. Firstly, the inflow of immigrants could add pressure to the labor supply. As a consequence, Spanish-born workers may be forced to accept more precarious working conditions in order not to lose their jobs, leading to an increase in the number of workplace accidents. Our results show the contrary. As such, we conclude that this channel is probably not relevant.

Secondly, the additional pressure from immigrants on the labor supply could force Spanish-born workers to underreport small workplace accidents if they are afraid of losing their jobs. Thus, immigrant inflows would imply a decrease in the number of reported workplace accidents by Spanish-born workers. However, Table 5 presents significant effects on the incidence of severe accidents, which are more difficult to hide or ignore. This suggests that reporting biases are not a very important concern, at least for natives during this time period.

Thirdly, immigrant inflows could substitute Spanish-born workers in jobs that have a higher injury risk. This would result in an improvement in workplace safety of the native population. In order to explore the plausibility of this channel, we analyze the effects of the inflow of the immigrant population on the total employment rate of both natives, as well as on the type of job that they have. In Table 7, we observe that the inflow of immigrants did not have any effect on the total employment rate of natives. This also holds true when we segregate the analysis by gender and by economic activity. This result is in line with previous literature (Altonji and Card 1991; Borjas 1995; Friedberg and Hunt 1995; Gonzalez and Ortega 2011). In addition, we explore whether the inflow of immigrants has an effect on the type of economic activities in which natives are employed. In Fig. 7, we show that, for the period 2004 to 2009, there is a decrease in the probability that Spanish-born workers are employed as domestic employees, low-medium rank officials in the armed forces, workers in the agrarian, farming, and fishing sectors, or in the extractive industry. At the same time, the probability of native workers being employed as managers with less than 10 employees, technicians, project managers, team leaders, or workers in the 
agriculture sector increases. In Table 8, using the O*NET classification, ${ }^{37}$ we classify the different occupations by the level of physical work conditions and the level of human interaction needed in these occupations. The classification goes from 1 to 15 . Those occupation with a lower number are characterized as being more physically intense, or requiring a higher level of human interaction. With this classification, we give suggestive evidence that, in the period 2004 to 2009, native workers reallocate from jobs with heavier physical demands (jobs with more exposure to hazardous equipment, minor burns, cuts, or bites, or that require protective or safety equipment) to jobs that entail more human interactions (jobs that require public speaking, use of letters and memos, face-to-face discussions, working in groups or teams, dealing with external customers, coordination, or supervision).

Therefore, we can conclude that the reduction in workplace accidents for native workers that took place from 2004 to 2009 was, at least partly, driven by the shift of Spanish-born workers from jobs with higher occupational risks to jobs with a lower risk of injury. This result is in line with the findings of Giuntella et al. (2019) for the UK and Dillender and McInerney (2020) for the USA.

For the period 2010 to 2015, we do not find any robust effect on workplace safety for the native population. We believe that the null effects for this period are driven by two possible mechanisms that are very related to the economic crisis that hit Spain during the period.

Firstly, the fear of losing the job during a period when employment was scarce could have reduced reporting of workplace accidents among native workers. However, we do not find effects on severe accidents during the period 2010-2015, which suggests that this mechanism could not fully explain the differences between the two periods.

Secondly, the economic crisis could have prevented any kind of shift between occupations due to the scarcity of jobs at the time. During the period 2010 to 2015, the total number of employed natives decreased by 2 million. Figure 7 shows that the probability that native workers are employed as technicians slightly decreases while the probability of native workers being employed as operators, professionals, or workers in construction or elementary occupations mildly increases. If anything, these changes in employment will predict an increase in workplace accidents although these shifts are probably too small to affect overall workplace safety.

Therefore, these results seem to indicate that immigration improves workplace safety of Spanish-born workers only if it leads to a reallocation of native workers from more physically intense to less manual occupations with lower injury risks.

Workplace accidents of immigrants We do not find any effect of immigration inflows on workplace safety of immigrants. Previous literature has pointed out that immigrants tend to be less educated, younger and healthier with respect to average native individuals (Borjas 1987; Antecol and Bedard 2006; Bertoli 2010; Moraga 2011; Kennedy et al. 2015; Giuntella and Mazzonna 2015; Farré 2016; Giuntella 2017).

\footnotetext{
${ }^{37}$ The Occupational Information Network $\left(\mathrm{O}^{*} \mathrm{NET}\right)$ contains a rich set of variables that describe work and worker characteristics, including skill requirements.
} 
In addition, the downward occupational mobility that immigrants experience after their arrival to Spain, makes them, in some cases, overqualified for the jobs they are performing.

It seems reasonable to assume that younger, healthier, and overqualified immigrant workers will engage in safer attitudes at the workplace compared with native workers. If this is true, we could expect the inflow of immigrants to improve workplace safety for natives without increasing the number of workplace accidents of immigrants. Given the limitations of our data, we are not able to fully explore this mechanism.

\subsection{Robustness check}

Multiple instrumentation procedure Jaeger et al. (2018) show that migration flows with high persistence pose a threat for the validity of the shift-share instrument. They claim that when the spatial distribution of immigrant flows is stable over time, the shift-share instrument will capture both the short and long-run responses of the immigration shocks. Jaeger et al. (2018) propose a "multiple instrumentation" procedure, that will allow to separately estimate the short- and long-run effects of immigration shocks. This "multiple instrumentation" procedure consists in adding a lag to the model to estimate the effect of contemporaneous immigration shocks (at time $t$ ) and past immigration shocks (at time $t-1$ ).

$$
\begin{aligned}
& \left(\frac{W A(t)_{r g}}{E(t)_{r g}}-\frac{W A(t-1)_{r g}}{E(t-1)_{r g}}\right) * 100,000=\alpha+\beta_{1} \frac{\left(M(t)_{r g e}-M(t-1)_{r g e}\right)}{1,000} \\
& +\beta_{2} \frac{\left(M(t-1)_{r g e}-M(t-2)_{r g e}\right)}{1,000}+\delta_{t}+\alpha_{r}+\mu_{g}+\gamma_{e}+\epsilon_{\text {trge }}
\end{aligned}
$$

where $\beta_{1}$ will still be our coefficient of interest, capturing the impact of immigration on workplace accidents in the short run, and $\beta_{2}$ captures the longer term reaction to past immigration shocks.

As both contemporaneous and past immigrant inflows are endogenous, we instrument them using the shift-share instrument and the lag of the shift-share instrument.

$$
\begin{aligned}
Z(t)_{r g e} & =\sum_{c=1}^{C} \Pi_{r c}\left(M(t)_{g e c}^{e s p}-M(t-1)_{g e c}^{\text {esp }}\right) \\
Z(t-1)_{r g e} & =\sum_{c=1}^{C} \Pi_{r c}\left(M(t-1)_{g e c}^{\text {esp }}-M(t-2)_{g e c}^{\text {esp }}\right)
\end{aligned}
$$

We then have two first-stage equations:

$$
\begin{aligned}
\frac{M(t)_{\text {rge }}-M(t-1)_{\text {rge }}}{1,000}= & \alpha+\beta_{1} \frac{Z(t)_{\text {rge }}}{1,000}+\beta_{2} \frac{Z(t-1)_{\text {rge }}}{1,000}+\delta_{t}+\alpha_{r} \\
& +\mu_{g}+\gamma_{e}+\epsilon_{\text {trge }} \\
\frac{M(t-1)_{\text {rge }}-M(t-2)_{\text {rge }}}{1,000}= & \alpha+\beta_{1} \frac{Z(t)_{\text {rge }}}{1,000}+\beta_{2} \frac{Z(t-1)_{\text {rge }}}{1,000}+\delta_{t}+\alpha_{r} \\
& +\mu_{g}+\gamma_{e}+\epsilon_{\text {trge }}
\end{aligned}
$$


$Z(t)_{\text {rge }}$ and $Z(t-1)_{\text {rge }}$ are both constructed using the distribution of immigrants in the Spanish provinces in 1991. Then, as suggested by Jaeger et al. (2018), the difference between the instruments will come from the variation over time in the composition of native inflows. To avoid the weak instrument problem in the two first stages, we would need the country of origin composition of migrants to change substantially across time. Recall that in Fig. 6, we have shown that the composition of immigrants in Spain by country of origin has indeed changed at four points of time. Another way of showing the change in the composition of immigrants over time is to calculate the correlation between the instruments. In Table 9, we observe that the correlation between the instrument $\left[Z(t)_{\text {rge }}\right]$ and the lag of the instrument $[Z(t-$ $1)_{\text {rge }}$ ] is 0.44 , indicating that in our context serial correlation is not an important issue. This is true for the two periods under consideration as well as when we split the sample by gender and education level of the immigrants. Moreover, we also show that, as expected, the correlation of the instrument with current immigrant inflows is larger (ranging from 0.43 to 0.76 ) than the correlation with lagged immigrant inflows ( -0.06 to 0.28 ). This provides further evidence that the composition of immigrants in Spain during the time considered in our analysis is changing enough.

In Tables 10 and 11, we can observe the two first stages. Table 10 shows that the coefficient of our instrument is highly significant and close to 1 , very similar to the estimates in the first stage regression in Table 2. On the other hand, the lagged instrument does not seem to be correlated with the contemporaneous immigration inflows. Notably, the F-statistic of the excluded instruments is also high, indicating that the instrument is strong. Similarly, Table 11 shows the first stage for the lagged immigration flows and the coefficient of the lagged instrument is significant and close to 1 , while the coefficient of the instrument is not significant or much smaller.

Table 12 reports the IV estimates for the main results. We find that the impact of recent immigration inflows on workplace accidents of Spanish-born workers is still negative and statistically significant for the period 2004 to 2009. In fact, the coefficients are quite similar to the estimates in our main specification in Table 3. An inflow of 1000 immigrants of a certain gender and educational level in a province decreases the number of workplace accidents by 8.67 (11.5 for men and 3.6 for women) for every 100,000 Spanish-born workers. However, the lagged immigrant inflow has no effect on workplace accidents, suggesting no long-term effect on workplace safety. For the period 2010 to 2015, we find that the small positive effect on workplace accidents of natives is coming from the lagged immigrant inflow, instead of the contemporaneous one. This indicates that for the period 2010 to 2015 there are no short-term effects of immigration over workplace accidents of natives. For each regression, we report the Kleibergen-Paap rk LM statistic for underidentification, ${ }^{38}$ which provides information on the difference in the predicted values from the two first stage regressions. For all the regressions for the period 2004-2009, we can reject the null hypothesis of underidentification.

\footnotetext{
${ }^{38}$ This statistic tests the null hypothesis that the rank of the matrix formed from the coefficient vectors from the first stage regressions is equal to 1 against the alternative that it is equal to 2 .
} 
We also look at the main heterogeneous effects (those that were significant in our main specification) in Table 13. In the first three columns, we report the effect of contemporaneous and lagged immigrant inflows on workplace accidents of Spanish-born workers for the period 2004 to 2009. We find that the effects of the contemporaneous immigrant inflows for mild, severe accidents or accidents occurring in the service sector are very robust to the inclusion of the lagged immigrant inflows. In columns 4 and 5, we look at the effect of immigrant inflows on mild workplace accidents and accidents occurring in the construction sector for the period 2010 to 2015 . We find that the inclusion of the lagged immigrant inflows affects a lot the effect of the contemporaneous immigrant inflows. In particular, the contemporaneous effect for mild accidents is no longer significant while the effect for construction is largely reduced.

Following these analyses, we can conclude that the shift-share instrument in our context for the period 2004 to 2009 only captures the short-run response of the immigration shocks.

Divinding migration flows and the instrument by the total population With our identification strategy, we are capturing the effect of an increase of 1000 immigrants of gender $g$ and skill group $e$ in province $r$ on the number of workplace accidents per 100,000 workers of gender $g$ in province $r$. One potential concern is that an inflow of 1000 immigrants in a large province may not have the same effect on safety as the same immigration inflow in a less populated province. We explored this possibility by re-estimating our main results dividing the actual immigration inflows and our instrument by the total population of gender $g$ and skill level $e$ living in province $r$ in the previous year $(t-1)$.

We estimate a alternative regression of the following form:

$$
\begin{gathered}
\left(\frac{W A(t)_{r g}}{E(t)_{r g}}-\frac{W A(t-1)_{r g}}{E(t-1)_{r g}}\right) * 100,000= \\
\alpha+\beta\left(\frac{M(t)_{r g e}-M(t-1)_{\text {rge }}}{P o p(t-1)_{\text {rge }}}\right) * 100 \\
+\delta_{t}+\alpha_{r}+\mu_{g}+\gamma_{e}+\epsilon_{\text {trge }}
\end{gathered}
$$

where we instrument the endogenous inflow of immigrants to the different provinces in Spain $\left(\frac{M(t)_{\text {rge }}-M(t-1)_{\text {rge }}}{\text { Pop }(t-1)_{\text {rge }}}\right)$ using:

$$
Z(t)_{r g e}=\frac{\sum_{c=1}^{C} Z(t)_{r g e c}}{\operatorname{Pop}(t-1)_{\text {rge }}}=\frac{\sum_{c=1}^{C} \Pi_{r c}\left(M(t)_{g e c}^{\text {esp }}-M(t-1)_{\text {gec }}^{\text {esp }}\right)}{\operatorname{Pop}(t-1)_{\text {rge }}}
$$

With this new specification, the main coefficient of interest $(\beta)$ is interpreted as the effect of an increase of $1 \%$ in the share of immigrants of gender $g$ and skill level $e$ in province $r$ over the share of workplace accidents per 100,000 workers of gender $g$ in province $r$.

Table 14 presents the results for Spanish-born individuals during the period 20042009. We find that a $1 \%$ increase in the share of immigrants of a certain gender and educational level in a province decreases the number of workplace accidents by 30 for every 100,000 Spanish-born workers. We also observe that the effect is larger for men, mild accidents, and accidents occurring in the service sector. We can conclude 
that the sign and significance of our main results are maintained using this alternative specification.

Opening the black box of the Bartik estimator Goldsmith-Pinkham et al. (2018) probe very nicely that the 2 SLS estimator using the Bartik instrument (or the shiftshare instrument) is numerically equivalent to a GMM estimator using the share of immigrants in 1990 in the different provinces of Spain as instruments and a weight matrix constructed from the national migration inflows. Then, our strategy is equivalent to an exposure research design, where the distribution of immigrants across the different provinces in 1990 measures the differential exogenous exposure to a common shock (migration inflows to Spain). For this exposure design to be credible, Goldsmith-Pinkham et al. (2018) suggest several tests.

We should be skeptical about the identifying assumptions if the distribution of immigrants in 1990 predict our main outcome (changes in workplace accidents) through a different channel than the one we are suggesting in our paper (Spanishborn workers shifting away from manual labor occupations). In our particular setting, we should be worried if the share of immigrants in the different provinces of Spain in 1990 is correlated with trends in the labor market characteristics of these provinces that could explain changes in the incidence of workplace accidents in 2003-2015. For instance, we can observe Table 1 that workplace accidents are more common in certain types of occupations and sectors. Moreover, the level of education might be correlated with the probability of suffering from a workplace accident. To alleviate these concerns, we use the Labor Force Survey (2004-2015) to construct a set of controls with characteristics of the labor market of each Spanish province across time. In particular, we have calculated the percentage of Spanish-born workers in the agriculture, industry, construction and services sectors, the percentage of Spanish individuals working in a high-skilled, semi-skilled white, semi-skilled blue, and lowskilled occupation, and the percentage of Spanish individuals with less than a high school degree, with a high school degree, and with college education. In Tables A13, A14, and A15 in the GLO working paper, we report the first stage and the main results for natives and immigrants adding the time-varying controls. We can observe that these controls barely affect our estimates. ${ }^{39}$

In addition, ${ }^{40}$ we can explore the validity of the design exploring how the Bartik instrument is combining all instruments. We can decompose the Bartik estimator into a weighted sum of the just-identified instrumental variable estimators that use each country of origin share $\left(\pi_{r c}\right)$ as a separate instrument. We do this for our sample where the data is only collapsed at the province and year level (as this is the level at which our shares vary). Goldsmith-Pinkham et al. (2018) show that $\hat{\beta}_{\text {Bartik }}=$ $\sum_{c} \hat{\alpha}_{c} \hat{\beta}_{c}$ where $\hat{\alpha}_{c}$ are the Rotemberg weights and $\hat{\beta}_{c}$ is the just-identified IV estimates based on each country of origin instrument. The validity of each $\hat{\beta}_{c}$ depends

\footnotetext{
${ }^{39}$ Note that we only control for these covariates as a robustness check and not in our main analysis because these controls might be partially endogenous.

${ }^{40}$ Goldsmith-Pinkham et al. (2018) also recommend looking at the pre-trends. We believe that this analysis might have been already addressed, in spirit, with the "multiple instrumentation" procedure.
} 
on the exogeneity of that country's instrument $\left(Z_{r c}\right)$. Importantly, if one instrument is misspecified, $\hat{\alpha}_{c}$ will tell us how much that misspecification translates into the overall bias of the Bartik instrument. Figure 8 shows graphically the heterogeneity in $\hat{\beta}_{c}$ and the relationship to the first stage f-statistic. Following Goldsmith-Pinkham et al. (2018), we have only included instruments with reasonable first-stage power (Fstatistic $>5)$. Also, to show how the $\hat{\beta}_{c}$ compare with the Bartik estimate, the figure includes a horizontal line that reflects the overall Bartik estimate. The individual points of $\hat{\beta}_{c}$ are weighted by the absolute size of the $\hat{\alpha}_{k}$ from the Bartik Rotemberg weights. Finally, we shaded the points differently depending on the sign of the Rotemberg weights. First, we can observe that the instruments with more weight correspond to South American countries, European countries outside the EU-12, and African countries. We have already pointed out in the introduction of our paper that South American and African immigrants had very distinct geographic distributions in 1991 driven by different non-economic reasons. This already suggest that the exogeneity assumption holds for the countries with more weight in our instrument. This is confirmed as the $\hat{\beta}_{c}$ of all these countries are quite close to the Bartik estimate. ${ }^{41}$ Thus, as all the high-weight countries are clustered very closely to the overall point estimate, we expect the potential misspecification of the other countries to generate only a very small bias in our estimates with the Bartik instrument.

\section{Conclusion}

In this paper, we explore the effects of immigration on workplace accidents of native and immigrant workers in Spain for the time period 2004 to 2015. Workplace accidents are important because they entail massive economic and social costs. They affect not only individuals involved in the accidents, but the society as a whole. However, they have been relatively unexplored in the previous literature studying the effects of migration flows.

Spain constitutes a perfect scenario to study this research question because it stands at a relatively bad position with respect to its European neighbors regarding workplace safety (Aibar 2006). In addition, Spain has been experiencing dramatic changes in immigration flows during that time period.

We follow an instrumental variable approach using immigrant clusters during the 1980s in Spain's provinces to distribute the current national inflow of immigrants from each country across the different provinces in Spain. From 2004 to 2015, we find that an inflow of 1000 immigrants decreases the incidence of workplace accidents by 4.2 for every 100,000 Spanish-born workers. This reduction is driven entirely by the period 2004 to 2009 , while migrant flows did not strongly affect workplace safety during the economic recession (2010-2015). For the time period 2004 to

\footnotetext{
${ }^{41}$ Moreover, we can also see that we have no negative weights. Note that negative Rotemberg weights will suggest that some of the underlying effects receive negative weight so that there is unlikely to be a LATE-like interpretation of the parameter estimate.
} 
2009, our results indicate that an inflow of 1000 immigrants decreases the proportion of workplace accidents by 9 for every 100,000 Spanish-born workers. Performing a simple back of the envelope calculation indicates that the inflow of immigrants during that time period decreased the number of working accidents suffered by the native population by 10,890 (a 7\% of the overall decrease during that period). Our administrative data allows us to analyze in detail the mechanisms behind the effects, as we have information on the gender, age, and nationality of the worker that suffered the accident, the job that he/she was performing at the time of the accident, and the level of severity of the accident. We find a reduction in both mild and severe accidents, supporting the idea that reporting biases are not an important concern, at least for natives during this time period. In addition, the reduction of workplace accidents is stronger in the service sector, where immigrants are more represented. ${ }^{42}$

We find that the reduction in the number of workplace accidents could be driven by the reallocation of native workers toward jobs that have lower injury risks. In particular, during 2004 to 2009, immigrant inflows reduce the employment rate of natives in occupations such as low or medium rank officers in the armed forces, workers in agricultural, farming, and fishing sectors, in the extractive industry, or in domestic work. These occupations, based on the $\mathrm{O} * \mathrm{NET}$ classification, are characterized by entailing a high physical burden. At the same time, the immigration inflows increase employment of natives as technicians and associate professionals, managers with less than 10 employees, or project managers and team leaders. These occupations are characterized by requiring a lot of human interaction. These results are consistent with those of Giuntella et al. (2019) for the UK and Dillender and McInerney (2020) for the USA.

We do not find a robust effect of migrant flows on workplace accidents of natives for the period 2010 to 2015. We believe the economic crisis of 2008, that hit Spain particularly hard, is behind the differences between the two periods, preventing strong shifts between occupations due to the scarcity of jobs at the time.

Finally, we do not find any effect of immigration on workplace safety of immigrants. This null effect goes in line with younger, healthier, and overqualified immigrant workers (due to self-selection and downward occupational mobility) engaging in safer attitudes at the workplace compared with native workers. Given the limitations of our data, we are not able to fully explore this mechanism.

The results of our study add a previously unexplored dimension to the immigration debate that should be taken into account when evaluating the costs and benefits of migration flows. In the conduct of our various analyses for this paper, we highlight the complexity of the immigration issue that has been dominating the political arena in recent years. We believe our results have relevant policy implications, in particular, for developed countries that receive large migration inflows.

\footnotetext{
${ }^{42} \mathrm{We}$ also find that the estimated effect is stronger when considering inflows of immigrants that have tertiary education. This could be explained by the downward occupational mobility that immigrants experience after their arrival to Spain.
} 
Funding Open Access funding provided by Projekt DEAL. This study was funded by the European Union H2020 REMINDER Project, and the Deutsche Forschungsgemeinschaft (DFG, German Research Foundation) through CRC TR 224 (Project A02).

\section{Compliance with ethical standards}

Conflict of interest The authors declare that they have no conflict of interest.

Open Access This article is licensed under a Creative Commons Attribution 4.0 International License, which permits use, sharing, adaptation, distribution and reproduction in any medium or format, as long as you give appropriate credit to the original author(s) and the source, provide a link to the Creative Commons licence, and indicate if changes were made. The images or other third party material in this article are included in the article's Creative Commons licence, unless indicated otherwise in a credit line to the material. If material is not included in the article's Creative Commons licence and your intended use is not permitted by statutory regulation or exceeds the permitted use, you will need to obtain permission directly from the copyright holder. To view a copy of this licence, visit http://creativecommonshorg/licenses/by/4.0/.

\section{Appendix: Tables and Figures}

Share of immigrants relative to population in Spain for the years 2003-2015

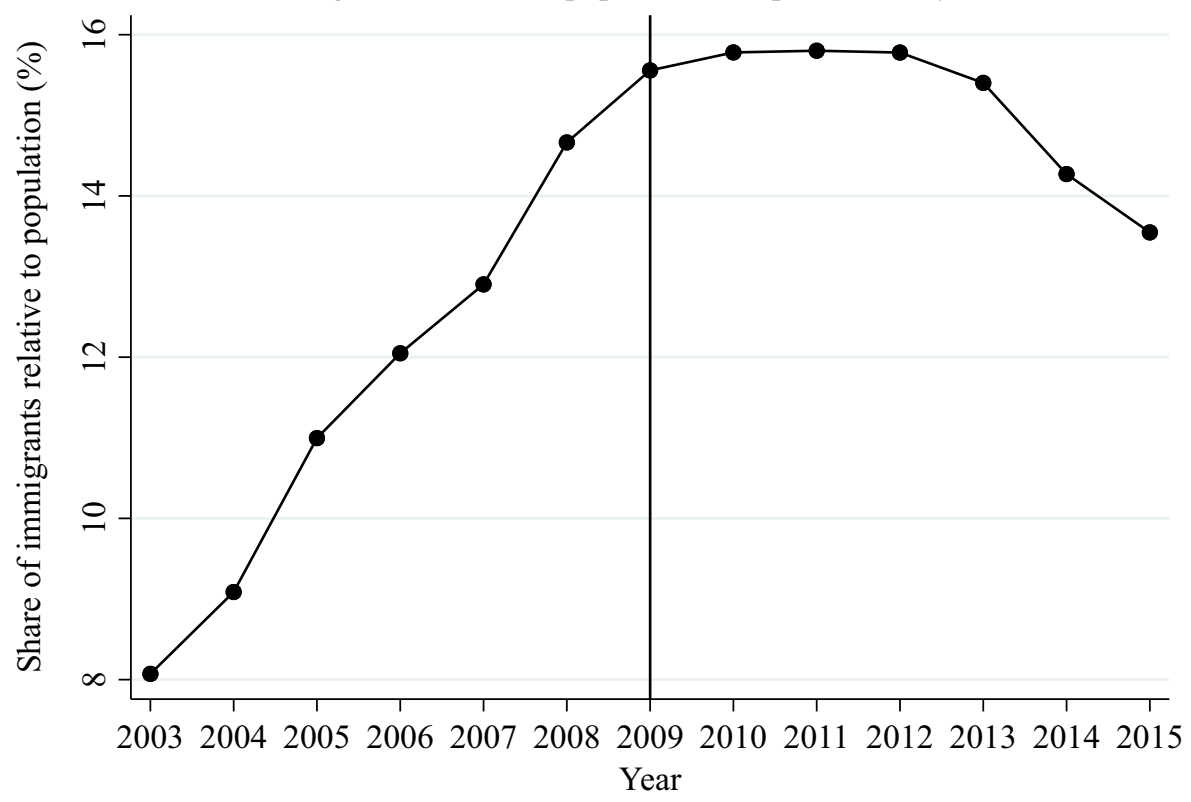

Fig. 1 Share of immigrants relative to the population in Spain (2003-2015). These graphs represent the evolution of the share of immigrants relative to the population (aged 25-54) in Spain from 2003 to 2015. Source: Spanish Population Census (2003-2015) 


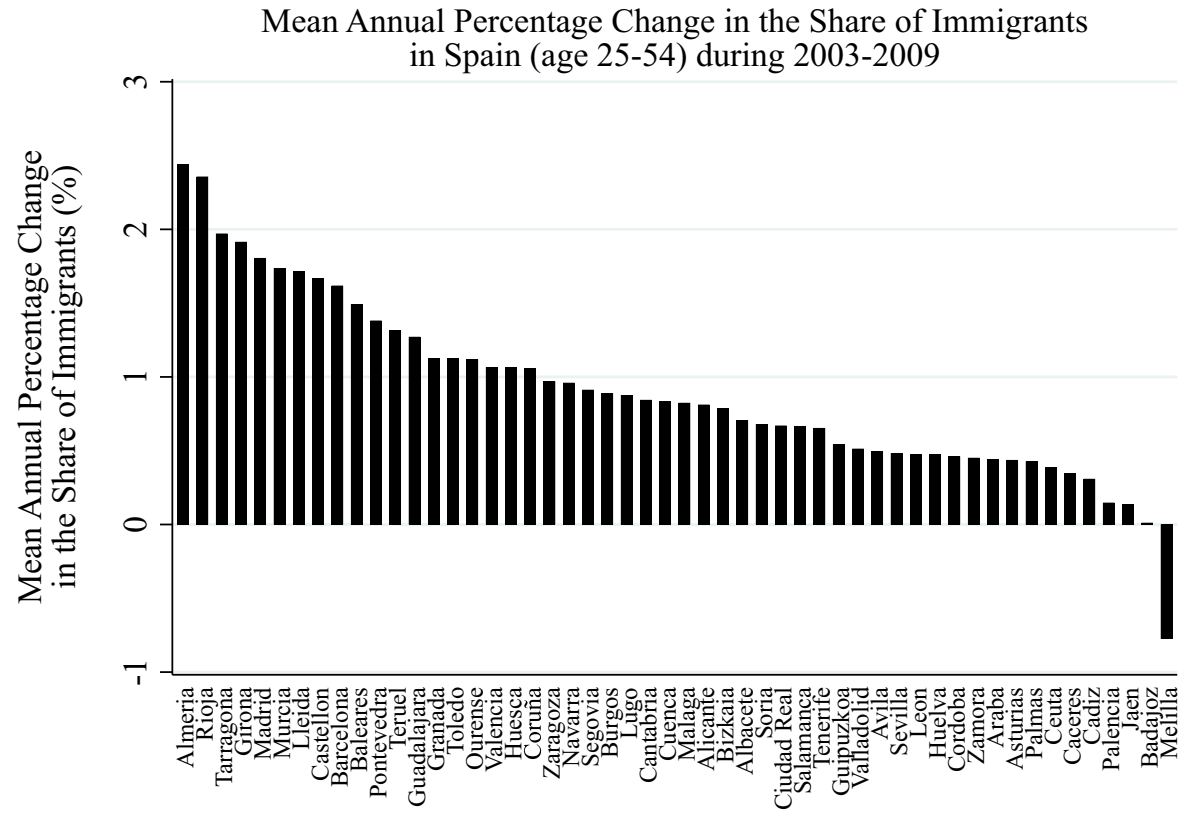

Fig. 2 Percentage change in the share of immigrants. These graphs represent the mean annual percentage change in the share of immigrants relative to the population (age 25-54) in the 52 provinces of Spain during two periods: 2003-2009 and 2010-2015. Source: Spanish Population Census (2003-2015)

Mean Annual Percentage Change in the Share of Immigrants in Spain (age 25-54) during 2010-2015

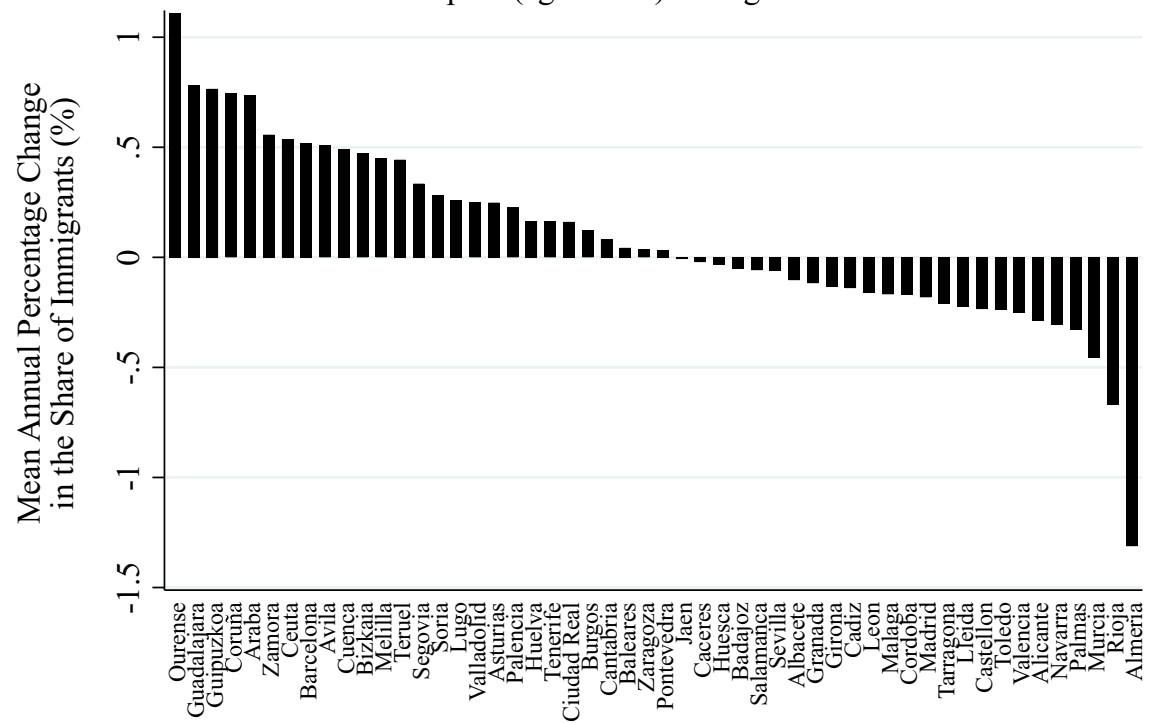

Fig. 3 Evolution of employment and workplace accidents in Spain. These graphs represent the evolution of the total number of employed individuals and the total number of workplace accidents of natives (graph above) and immigrants (graph below) during the period of 2003 to 2015 in Spain. Source: Register of Workplace Accidents (2003-2015) and Spanish Labor Force Survey (2003-2015) 
Table 1 Descriptive statistics of workplace accidents per worker

\begin{tabular}{|c|c|c|c|c|c|c|c|c|c|c|}
\hline & \multicolumn{5}{|c|}{ Period 2003-2009 } & \multicolumn{5}{|c|}{ Period 2010-2015 } \\
\hline & Mean & Std. Dev & Min. & Max. & Total & Mean & Std. Dev & Min. & Max. & Total \\
\hline \multicolumn{11}{|c|}{ Workplace accidents per worker $(* 100)$ for nationals } \\
\hline Total & 4.37 & 1.10 & 1.94 & 10.03 & 1591.62 & 2.89 & 0.59 & 1.77 & 4.84 & 903.04 \\
\hline Men & 5.53 & 1.46 & 2.08 & 11.89 & 2013.52 & 3.57 & 0.79 & 1.69 & 6.34 & 1114.00 \\
\hline Women & 2.61 & 0.72 & 1.25 & 6.72 & 950.68 & 2.04 & 0.49 & 1.05 & 3.51 & 637.88 \\
\hline Agriculture & 3.69 & 2.51 & 0.00 & 17.13 & 1344.80 & 3.86 & 2.66 & 0.00 & 29.30 & 1205.86 \\
\hline Industry & 6.70 & 2.43 & 1.50 & 19.48 & 2437.25 & 4.48 & 1.93 & 0.00 & 21.91 & 1397.92 \\
\hline Construction & 11.19 & 3.48 & 4.41 & 20.94 & 4072.99 & 5.49 & 2.18 & 0.00 & 29.59 & 1713.06 \\
\hline Services & 2.73 & 0.76 & 1.28 & 6.69 & 994.89 & 2.34 & 0.55 & 1.32 & 4.16 & 730.13 \\
\hline Mild & 4.31 & 1.09 & 1.88 & 9.91 & 1570.17 & 2.86 & 0.59 & 1.75 & 4.81 & 893.52 \\
\hline Severe & 0.06 & 0.02 & 0.02 & 0.16 & 21.45 & 0.03 & 0.01 & 0.00 & 0.08 & 9.51 \\
\hline \multicolumn{11}{|c|}{ Workplace accidents per worker $(* 100)$ for immigrants } \\
\hline Total & 4.69 & 2.83 & 0.56 & 19.04 & 1707.31 & 2.36 & 1.06 & 0.56 & 6.94 & 736.28 \\
\hline Men & 7.00 & 4.69 & 1.05 & 36.52 & 2549.61 & 3.66 & 2.20 & 0.82 & 22.36 & 1142.94 \\
\hline Women & 1.87 & 1.32 & 0.00 & 9.21 & 680.27 & 1.16 & 0.55 & 0.27 & 3.18 & 360.49 \\
\hline Agriculture & 5.46 & 6.82 & 0.00 & 51.01 & 1986.00 & 6.39 & 7.63 & 0.00 & 65.13 & 1994.07 \\
\hline Industry & 8.01 & 12.83 & 0.00 & 191.59 & 2915.66 & 4.19 & 5.09 & 0.00 & 47.07 & 1306.28 \\
\hline Construction & 11.67 & 11.25 & 0.00 & 91.40 & 4248.91 & 5.12 & 4.42 & 0.00 & 24.76 & 1596.22 \\
\hline Services & 2.43 & 1.61 & 0.17 & 11.09 & 883.27 & 1.60 & 1.10 & 0.43 & 12.16 & 498.86 \\
\hline Mild & 4.61 & 2.78 & 0.53 & 19.04 & 1679.47 & 2.33 & 1.05 & 0.56 & 6.82 & 726.11 \\
\hline Severe & 0.08 & 0.07 & 0.00 & 0.68 & 27.84 & 0.03 & 0.03 & 0.00 & 0.17 & 10.16 \\
\hline
\end{tabular}

This table reports the mean, standard deviation, minimum, maximum, and total number of workplace accidents per worker (multiplied by 100) for natives and immigrants collapsed at the province and year level for two time periods: from 2003 to 2009 and 2010 to 2015. There are 364 observations for the period 2003-2009 and 312 for 2010-2015. Source: Register of Workplace Accidents (2003-2015) and Spanish Labor Force Survey (2003-2015) 


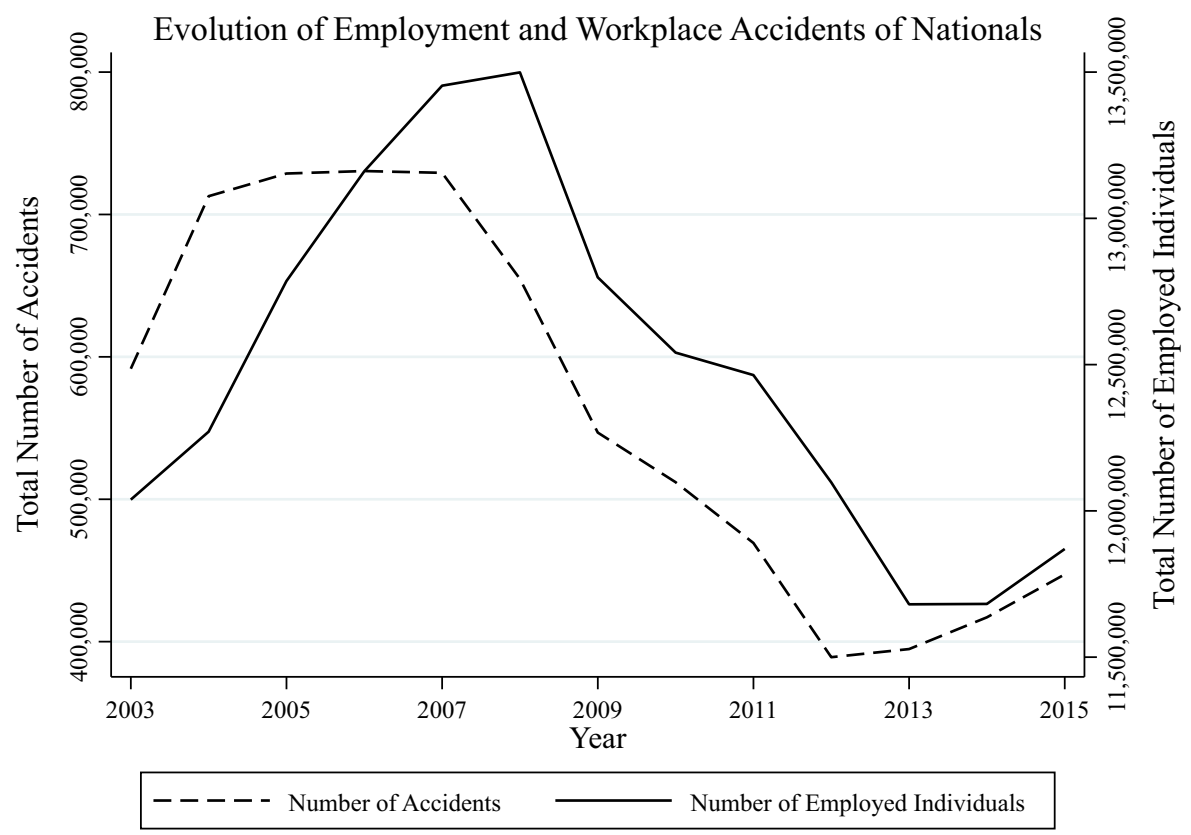

Fig. 4 Distribution of immigrants across the regions of Spain in 1991. These maps show the distribution of immigrants across the provinces of Spain by region of origin in 1991. Source: Census (1991)

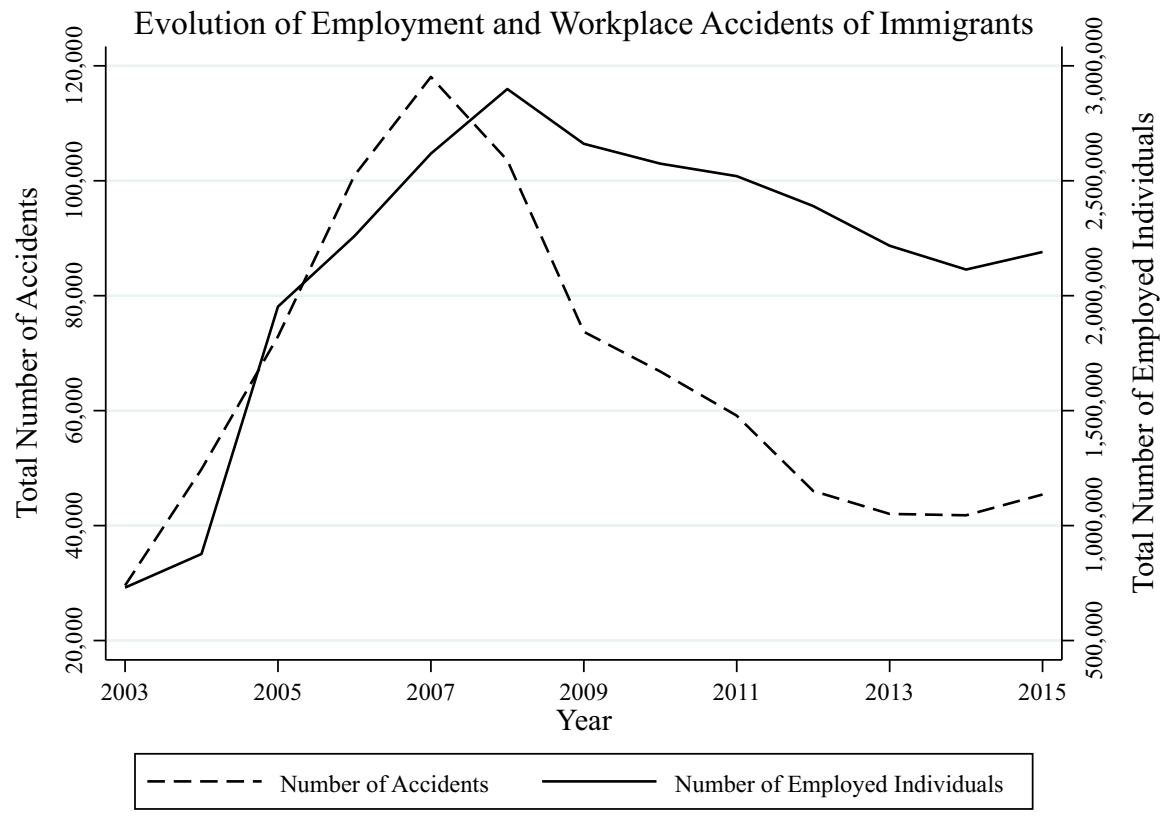

Fig. 5 Correlation between the distribution of immigrants across spanish provinces in 1991 and 2006 or 2015. These graphs represent the correlation between the share of immigrants of country $c$ living in province $r$ in 1991 and in 2006 (graph above) or 2015 (graph below). Spanish Labor Force Survey (2006 and 2015) and Census (1991) 


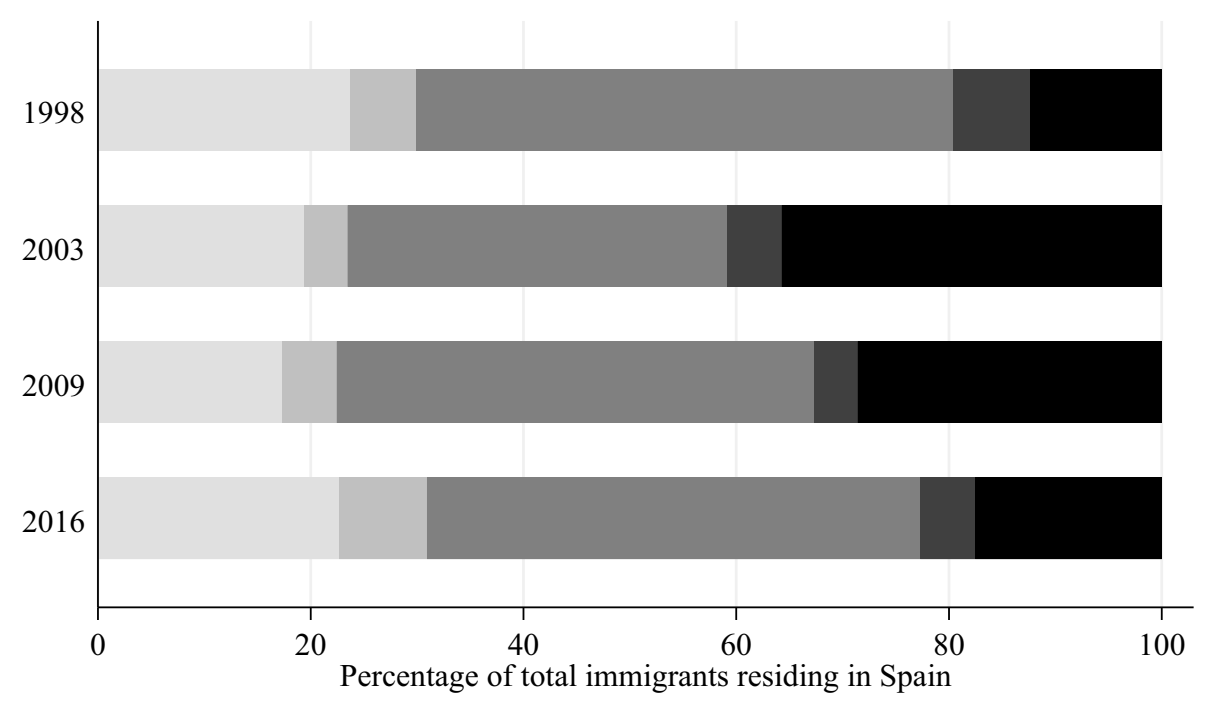

\begin{tabular}{|l|l|}
\hline Africa & Asia \\
Europe & North-Central America \\
South America & \\
\hline
\end{tabular}

Fig. 6 Immigrants residing in Spain by region of origin. Percentage of total immigrants residing in Spain by country of origin at four points in time: 1998, 2003, 2009, and 2016. Source: Spanish Population Census (1998, 2003, 2009, and 2016) 


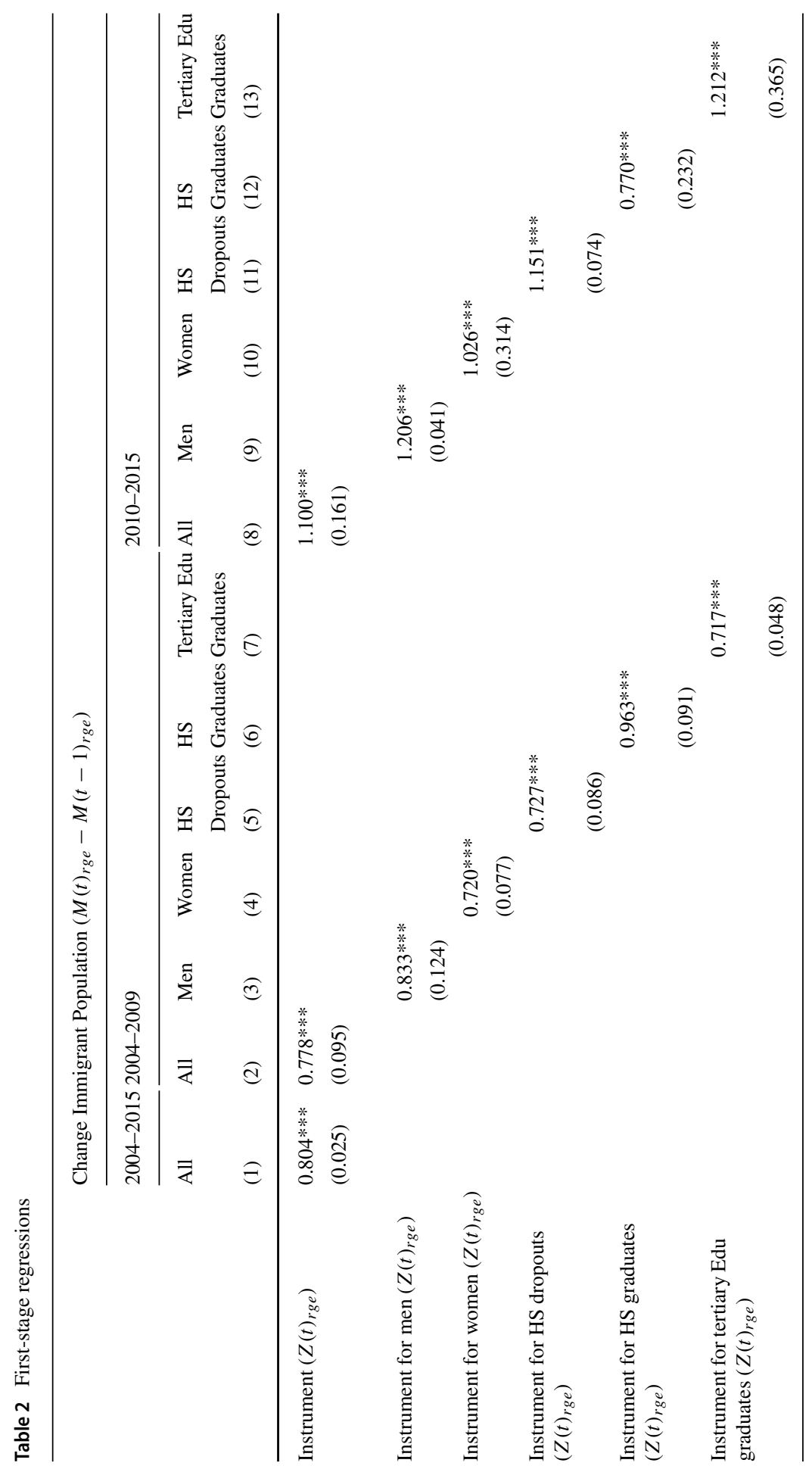




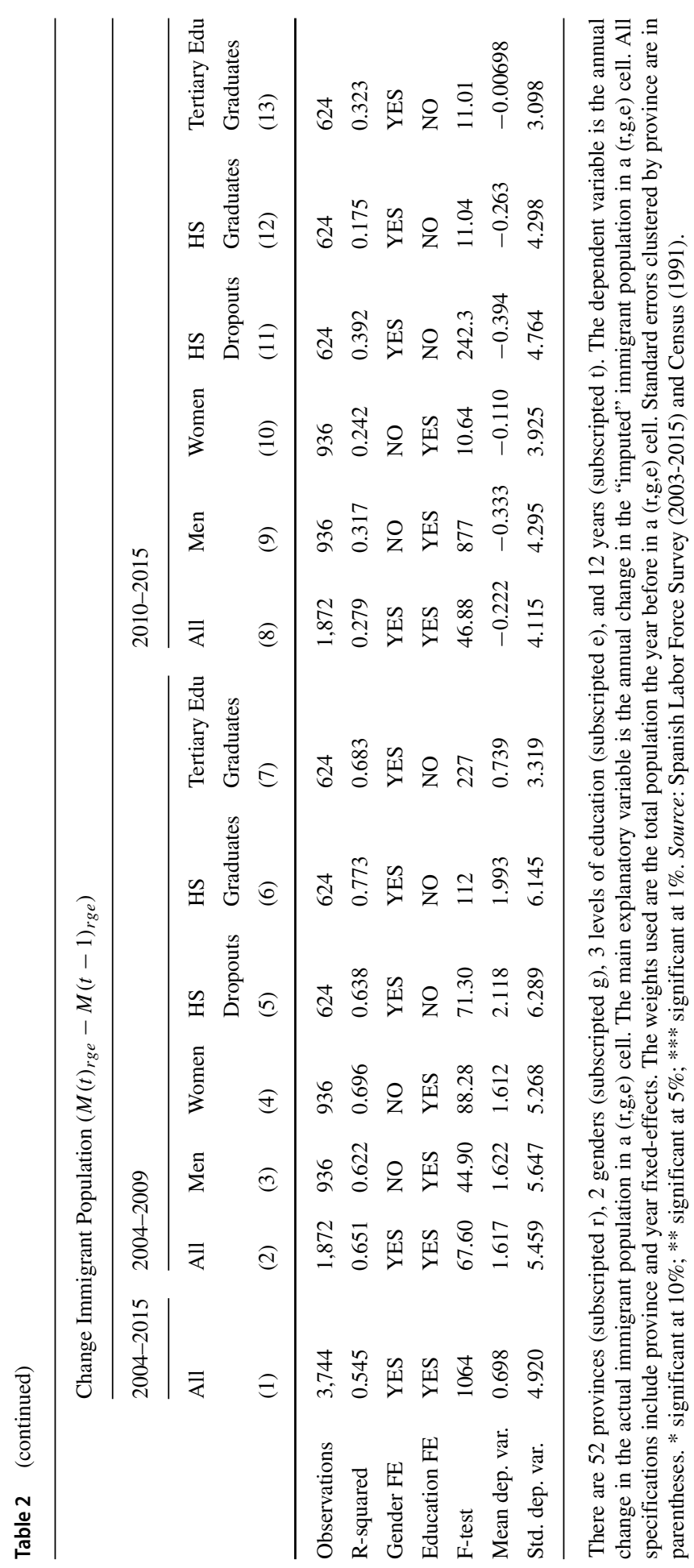


Table 3 Workplace accidents of Spanish-born workers

Change workplace accidents per Spanish-born worker

$$
\left(\frac{W A(t)_{r g}}{E(t)_{r g}}-\frac{W A(t-1)_{r g}}{E(t-1)_{r g}} * 100,000\right)
$$

\begin{tabular}{|c|c|c|c|c|c|c|}
\hline \multirow{2}{*}{$\begin{array}{l}2004-2015 \\
\text { All }\end{array}$} & \multicolumn{3}{|c|}{ 2004-2009 } & \multicolumn{3}{|c|}{ 2010-2015 } \\
\hline & All & Men & Women & All & Men & Women \\
\hline (1) & (2) & (3) & (4) & (5) & (6) & (7) \\
\hline
\end{tabular}

OLS:

$\begin{array}{lll}\text { Immigrant inflows } & -0.287 & -2.463^{* *} \\ & (0.677) & (1.169)\end{array}$

Immigrant inflows of men

Immigrant inflows of women

IV:

Immigrant inflows

$$
\begin{array}{ll}
-4.258^{* * *} & -8.858 * * * \\
(1.115) & (1.634)
\end{array}
$$

Immigrant inflows of men

Immigrant inflows of women

\begin{tabular}{llllllll} 
& & & & $(1.661)$ & & & $(0.586)$ \\
Observations & 3,744 & 1,872 & 936 & 936 & 1,872 & 936 & 936 \\
R-squared & 0.490 & 0.486 & 0.603 & 0.398 & 0.615 & 0.700 & 0.630 \\
Gender FE & YES & YES & NO & NO & YES & NO & NO \\
First-stage F & 911.4 & 82.30 & 61.87 & 97.22 & 46.03 & 313.1 & 12.03 \\
Mean dep. var. & -69.45 & -57.62 & -113.1 & -2.130 & -81.27 & -127 & -35.56 \\
Std. dep. var. & 560.5 & 704.4 & 873.4 & 473.1 & 363.4 & 445.7 & 247.9 \\
\hline
\end{tabular}

There are 52 provinces (subscripted r), 2 genders (subscripted g), 3 levels of education (subscripted e), and 12 years (subscripted $\mathrm{t}$ ). The dependent variable is the annual change in the number of workplace accidents per 100,000 Spanish-born workers in a (r,g) cell. The main explanatory variable is the annual change in the "imputed" immigrant population in a $(r, g, e)$ cell. All specifications include province, year, and education fixed-effects. The weights used are the number of native employees in a (r,g) cell. Standard errors clustered by province are in parentheses. * significant at $10 \%$; ** significant at 5\%; *** significant at 1\%. Source: Register of workplace accidents (2003-2015), Spanish Labor Force Survey (2003-2015), and Census (1991) 
Table 4 Workplace accidents of immigrant workers

Change workplace accidents per immigrant worker

$$
\left(\frac{W A(t)_{r g}}{E(t)_{r g}}-\frac{W A(t-1)_{r g}}{E(t-1)_{r g}} * 100,000\right)
$$

\begin{tabular}{lllllll}
$2004-20152004-2009$ & \multicolumn{5}{c}{$2010-2015$} \\
\hline All & All & Men & Women & All & Men & Women \\
$(1)$ & $(2)$ & $(3)$ & $(4)$ & $(5)$ & $(6)$ & (7)
\end{tabular}

\section{OLS:}

Immigrant inflows

$$
-7.834-15.916^{* * *}
$$

Immigrant inflows of men

$$
-19.364^{*}
$$

(11.448)

Immigrant inflows of women

$$
-10.777 * * *
$$

$$
\text { (3.605) }
$$

IV:

Immigrant inflows

$$
\begin{array}{ll}
4.388 & -1.161 \\
(9.950) & (19.797)
\end{array}
$$

Immigrant inflows of men

$$
-3.191
$$

$$
\text { (31.026) }
$$

Immigrant inflows of women

\section{Observations}

936

R-squared

\section{Gender FE}

YES

YES

NO

NO

YES

$\mathrm{NO} \mathrm{NO}$

First-stage F

$1020 \quad 60.50$

44.65

66.34

52.50

$267.6 \quad 14.13$

Mean dep. var.

$-178.4-190.3$

$-340.4$

$-166.4-268.6-64.27$

Std. dep. var.

$2638 \quad 3321$

4551

1143

1701

$2356 \quad 467.6$

There are 52 provinces (subscripted r), 2 genders (subscripted g), 3 levels of education (subscripted e), and 12 years (subscripted $\mathrm{t}$ ). The dependent variable is the annual change in the number of workplace accidents per 100,000 foreign-born workers in a $(\mathrm{r}, \mathrm{g})$ cell. The main explanatory variable is the annual change in the "imputed" immigrant population in a (r,g,e) cell. All specifications include province, year, and education fixed-effects. The weights used are the number of immigrant employees in a (r,g) cell. Standard errors clustered by province are in parentheses. * significant at $10 \%$; ** significant at $5 \%$; *** significant at 1\%. Source: Register of Workplace Accidents (2003-2015), Spanish Labor Force Survey (2003-2015), and Census (1991). 
Table 5 Workplace accidents of Spanish-born workers by level of severity

Change workplace accidents per Spanish-born worker

$$
\left(\frac{W A(t)_{r g s}}{E(t)_{r g}}-\frac{W A(t-1)_{r g s}}{E(t-1)_{r g}} * 100,000\right)
$$

\begin{tabular}{|c|c|c|c|}
\hline \multicolumn{2}{|l|}{ Mild } & \multicolumn{2}{|l|}{ Severe } \\
\hline 2004-2009 & 2010-2015 & 2004-2009 & 2010-2015 \\
\hline (1) & (2) & (3) & (4) \\
\hline
\end{tabular}

\section{OLS:}

Immigrant inflows

$$
-2.329^{* *}
$$

$2.922 * *$

$$
-0.134 * * *
$$

$(0.042)$

IV:

\begin{tabular}{lllll} 
Immigrant inflows & $-8.579^{* * *}$ & $1.933^{* * *}$ & $-0.279^{* * *}$ & 0.015 \\
& $(1.620)$ & $(0.632)$ & $(0.062)$ & $(0.027)$ \\
Observations & 1,872 & 1,872 & 1,872 & 1,872 \\
R-squared & 0.485 & 0.618 & 0.269 & 0.067 \\
First-stage F & 82.30 & 46.03 & 82.30 & 46.03 \\
Mean dep. var. & -53.12 & -80.01 & -4.497 & -1.262 \\
Std. dep. var. & 696.9 & 360.7 & 16.79 & 12.44 \\
\hline
\end{tabular}

There are 52 provinces (subscripted r), 2 genders (subscripted g), 3 levels of education (subscripted e), 12 years (subscripted $t$ ), and 2 levels of severity (subscripted $s$ ). The dependent variable is the annual change in the number of workplace accidents per 100,000 Spanish-born workers in a (r,g,s) cell. The main explanatory variable is the annual change in the "imputed" immigrant population in a (r,g,e) cell. All specifications include province, year, gender, and education fixed-effects. The weights used are the number of native employees in a $(\mathrm{r}, \mathrm{g})$ cell. Standard errors clustered by province are in parentheses. * significant at $10 \%$; ** significant at 5\%; *** significant at $1 \%$. Source: Register of Workplace Accidents (2003-2015), Spanish Labor Force Survey (2003-2015), and Census (1991) 


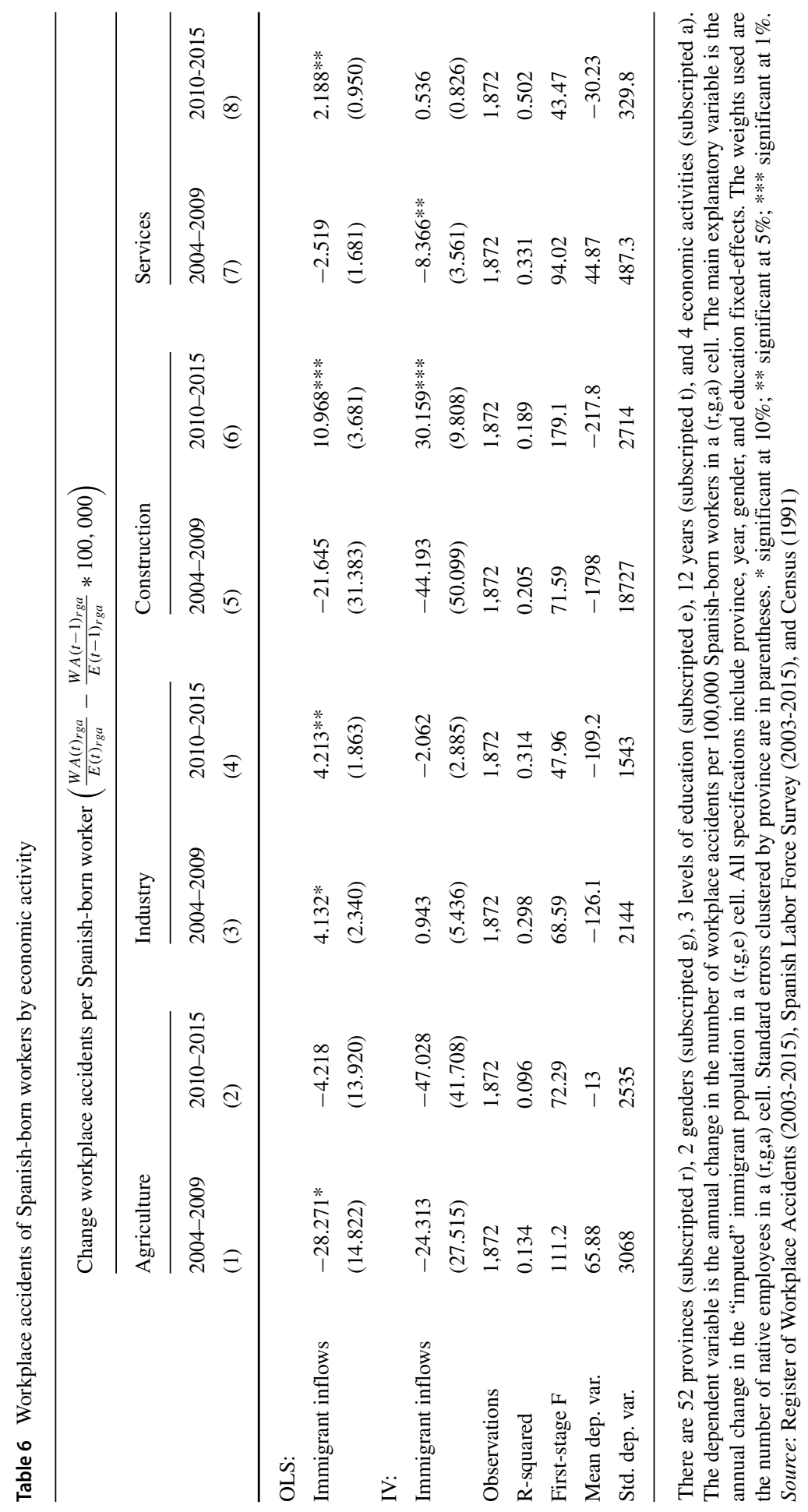




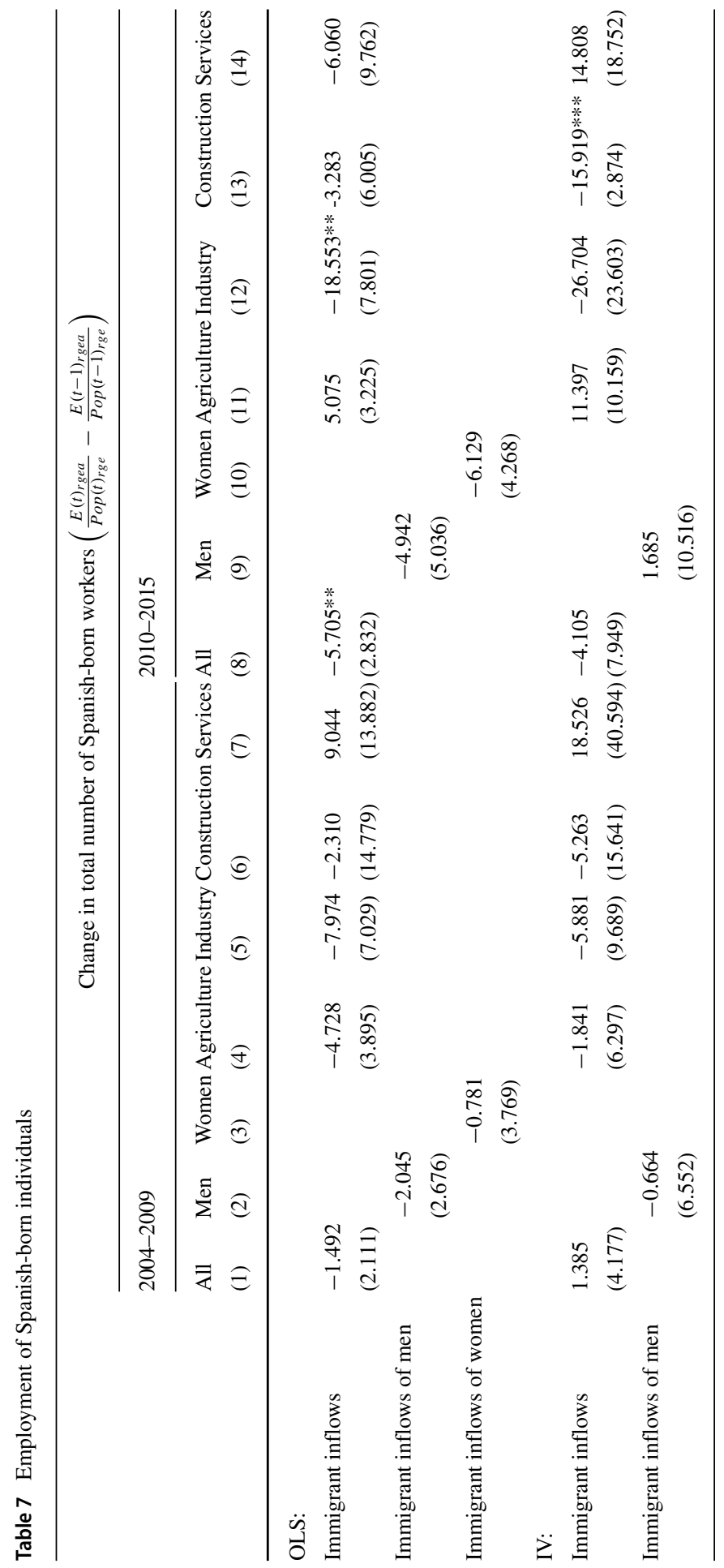




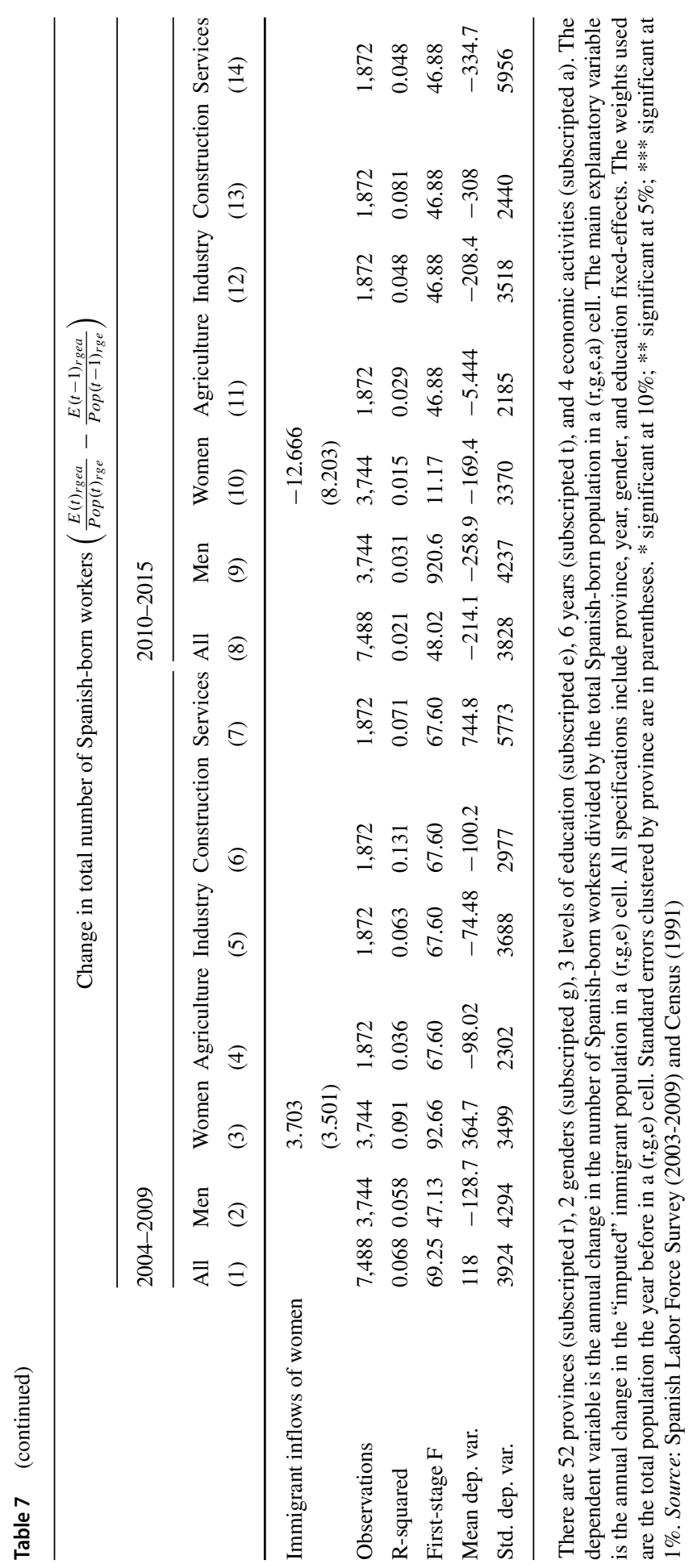



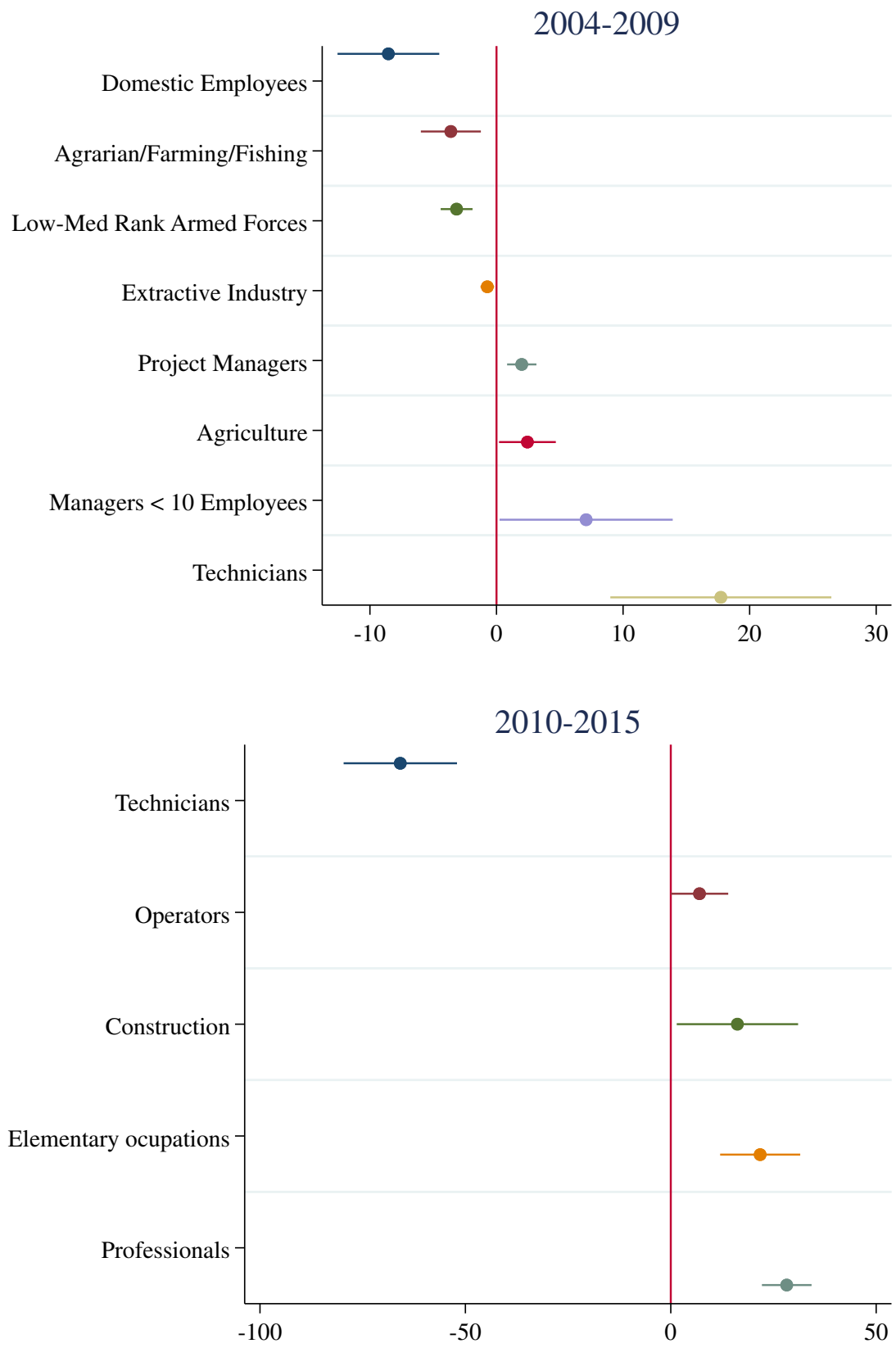

Fig. 7 Employment of Spanish-born individuals by type of occupation. The graph plots the estimated coefficient and the $95 \%$ interval of the IV regression where the dependent variable is the annual change in the total number of Spanish-born workers divided by the number of Spanish-born population in a $(r, g, o)$ cell. The main explanatory variable is the annual change in the "imputed" immigrant population in a $(\mathrm{r}, \mathrm{g})$ cell. All specifications include province, year, and gender fixed effects. The weights used are the total population the year before in a $(\mathrm{r}, \mathrm{g})$ cell. Standard errors are clustered the province level. Source: Spanish Labor Force Survey (2003-2009) and Census (1991) 
Table 8 Occupation classification by job environment

\begin{tabular}{|c|c|c|c|c|c|c|c|c|c|}
\hline & Public Speaking & Letters and Memos & $\begin{array}{l}\text { Face-to-Face } \\
\text { Diseussions }\end{array}$ & $\begin{array}{l}\text { Work With Work } \\
\text { Group or Team }\end{array}$ & \begin{tabular}{|c|} 
Deal With External \\
Customers
\end{tabular} & $\begin{array}{c}\text { Coordinate or Lead } \\
\text { Others }\end{array}$ & $\begin{array}{l}\text { Exposed to } \\
\text { Hazardous } \\
\text { Equipment }\end{array}$ & \begin{tabular}{|c|} 
Exposed to Minor \\
Burns, Cuts, \\
Bites..
\end{tabular} & $\begin{array}{c}\text { Wear Common } \\
\text { Protective or } \\
\text { Safety Equipment }\end{array}$ \\
\hline Public Adm_ Or Managers with $>10$ workers & 1 & 1 & 1 & 1 & 3 & 1 & 12 & 13 & 13 \\
\hline Managers $<10$ norkers & 5 & 5 & 4 & 3 & 5 & 3 & 10 & 10 & 10 \\
\hline Professionals & 2 & 2 & 2 & 4 & 6 & 2 & 15 & 15 & 15 \\
\hline Technicians & 3 & 3 & 3 & 5 & 4 & 5 & 13 & 12 & 12 \\
\hline Administrative & 7 & 4 & 6 & 7 & 1 & 7 & 14 & 14 & 14 \\
\hline Catering, Personal, Protection and Sellers & 4 & 6 & 8 & 2 & 2 & 4 & 11 & 11 & 11 \\
\hline Agriculture & 15 & 14 & 15 & 14 & 12 & 15 & 4 & 2 & 1 \\
\hline Agrarian, Farming and Fishing industry & 14 & 13 & 14 & 15 & 15 & 14 & 6 & 4 & 6 \\
\hline Project Managers and Team Leaders & 6 & 7 & 5 & 6 & 9 & 6 & 8 & 9 & 8 \\
\hline Construction Workers & 12 & 9 & 7 & 12 & 10 & 9 & 1 & 3 & 2 \\
\hline Metallurgy and machine construction & 13 & 12 & 10 & 13 & 14 & 13 & 2 & 5 & 4 \\
\hline Fatractive lndustry & 8 & 10 & 9 & 11 & 13 & 10 & 3 & 6 & 5 \\
\hline Operators & 9 & 11 & 11 & 10 & 11 & 11 & 5 & 7 & 7 \\
\hline Domestic Employees & 11 & 15 & 13 & 8 & 8 & 8 & 7 & 1 & 3 \\
\hline Other non-qualified Workers & 10 & 8 & 12 & 9 & 7 & 12 & 9 & 8 & 9 \\
\hline
\end{tabular}

Classification of the different occupations by some of their job environment. These characteristics take into account the interactions between the worker and the physical job environment, as well as, the different human interaction processes. "Public Speaking" classifies occupation depending on how often workers have to perform public speaking during their job. "Letters and Memos" classifies occupations depending on how often the job requires written letters and memos. "Face-to-Face Discussions" classifies occupations depending on how often workers have to have face-to-face discussions with individuals or teams in their job. "Work With Work Group or Team" classifies occupations depending on how important it is to work with others in a group or team in this job. "Deal With External Customers" classifies occupations depending on how important it is to work with external customers or the public in this job. "Coordinate or Lead Others" classifies occupations depending on how important it is to coordinate or lead others in accomplishing work activities in this job. "Exposed to Hazardous Equipment " classifies occupations depending on how often this job requires exposure to hazardous equipment. "Exposed to Minor Burns, Cuts, Bites..." classifies occupations depending on how often this job requires exposure to minor burns, cuts, bites, or stings. "Wear Common Protective or Safety Equipment" classifies occupations depending on how much this job requires wearing common protective or safety equipment such as safety shoes, glasses, gloves, hard hats or life jackets. The classification goes from 1 to 15 , where occupations get a lower point value if these characteristics and requirements are more important for the occupation. Source: "Work Context" O*NET OnLine, National Center for O*NET Development www.onetonline.org and Spanish Labor Force Survey (2003-2009) 


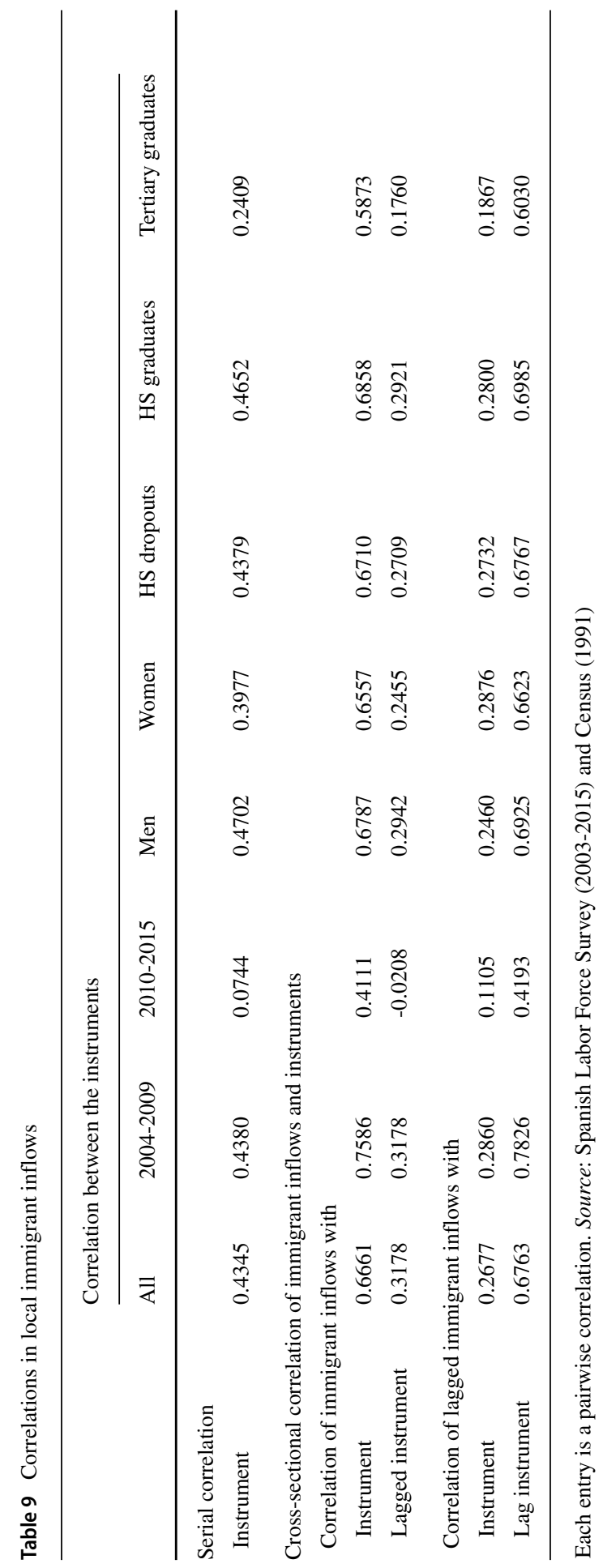




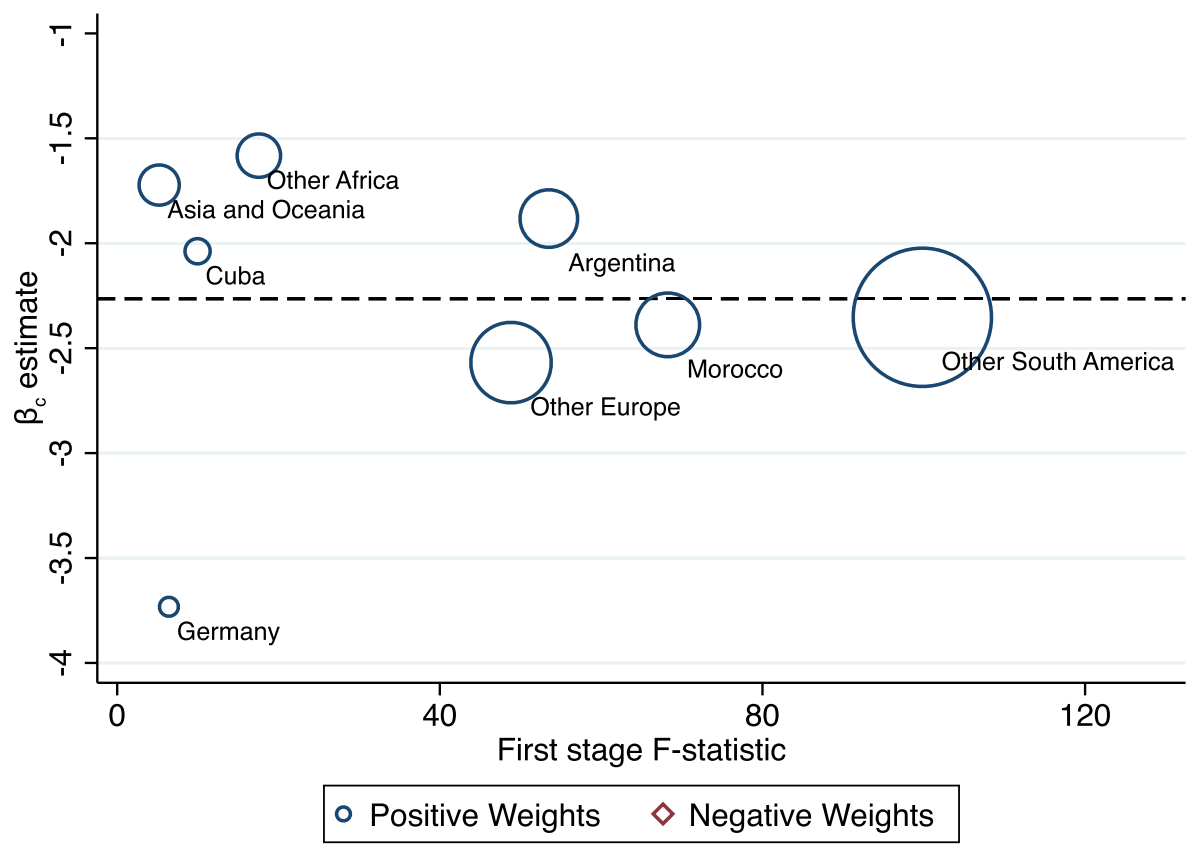

Fig. 8 Heterogeneity of $\beta_{k}$ for the period 2004-2009. This figure plots the estimated $\hat{\beta}_{c}$ for each instrument on the $y$-axis and the estimated first-stage F-statistic on the $\mathrm{x}$-axis. The size of the points are scales by the magnitude of the Rotemberg weights. The circles denote positive Rotemberg weights while the diamonds indicate negative weights. The horizontal dashed line indicates the the estimated $\hat{\beta}$ using the Bartik instrument. This figure only includes instruments with a first-stage F-statistics above 5. Source: Spanish Labor Force Survey (2003-2009) and Census (1991) 


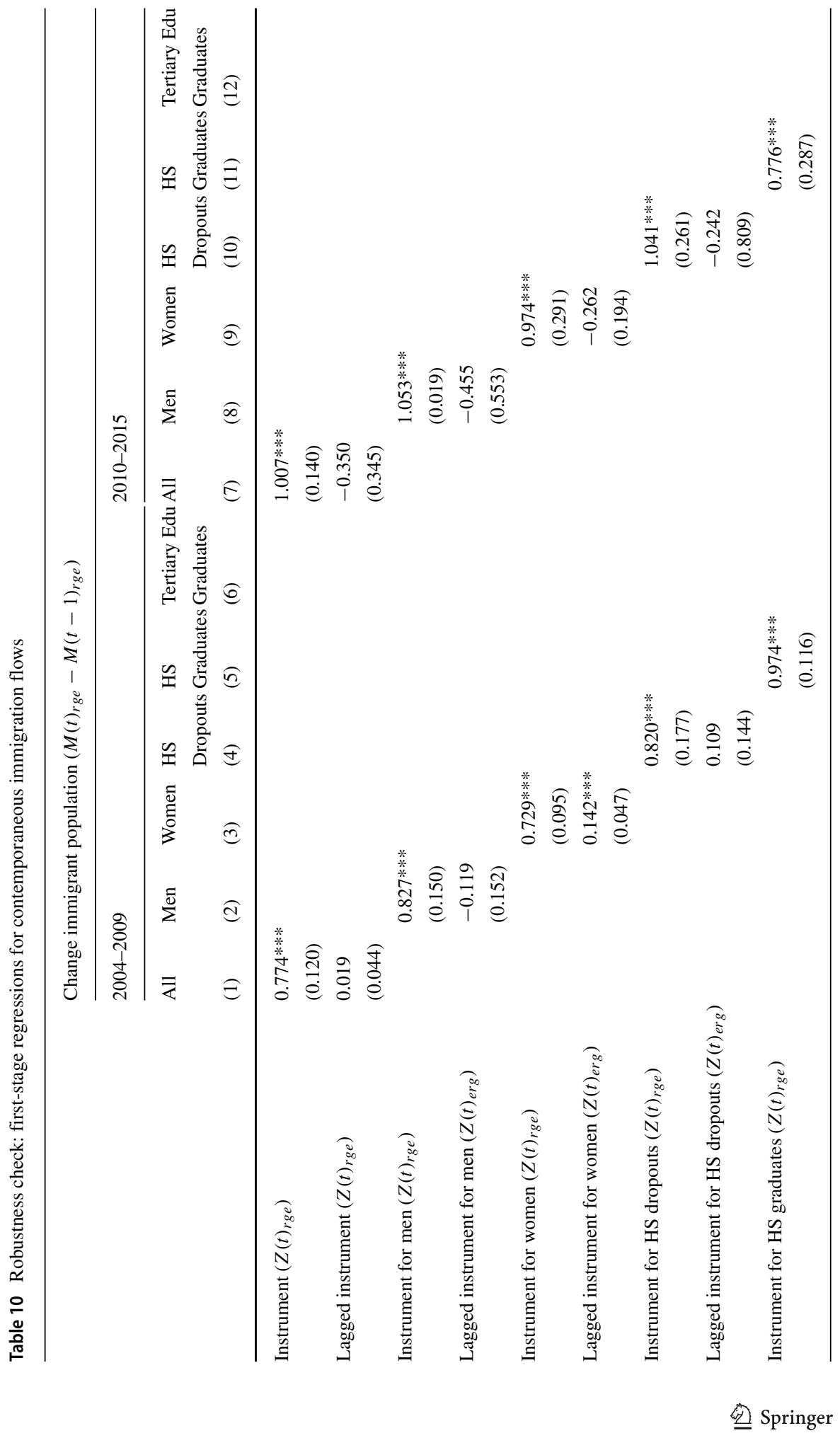




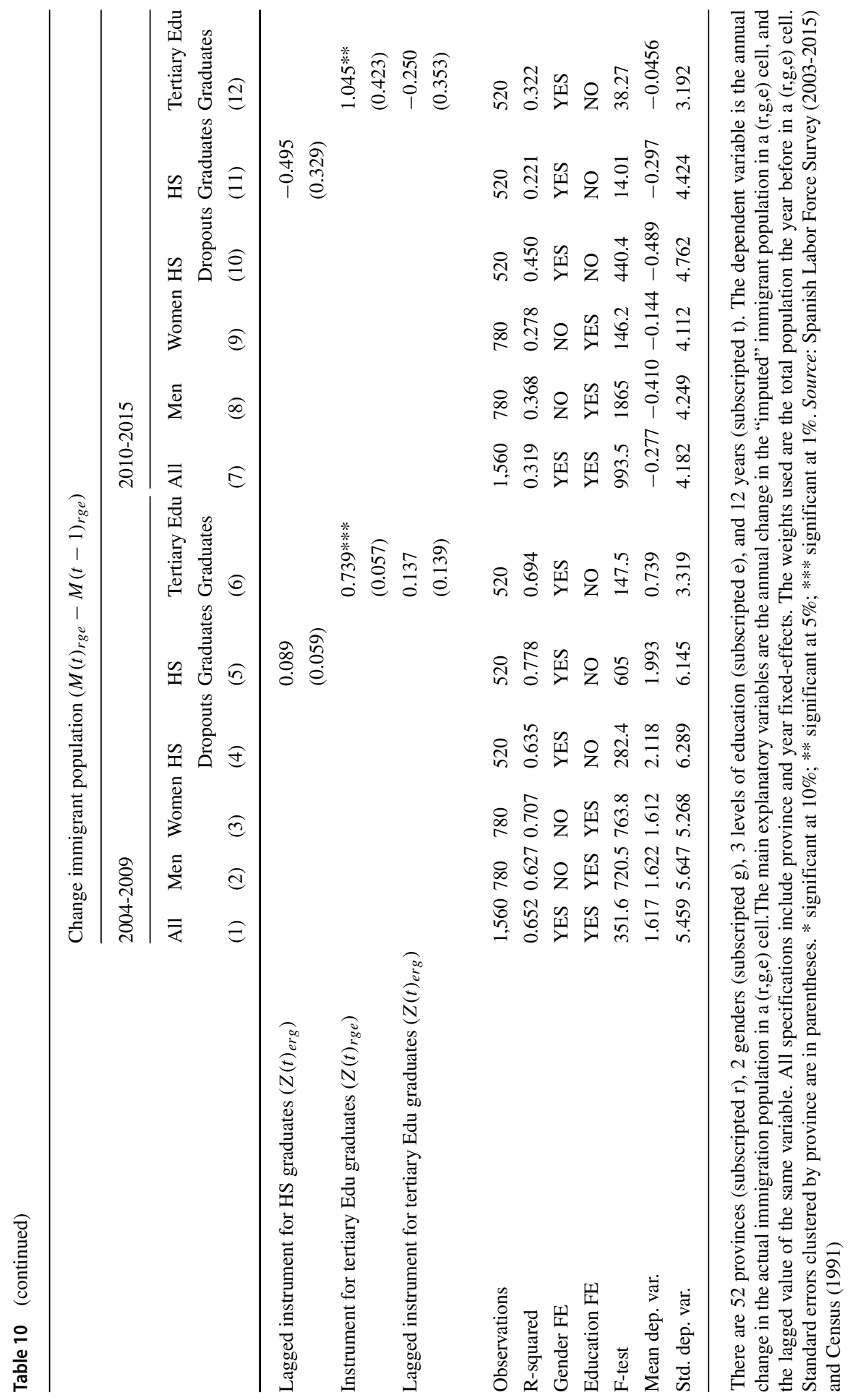




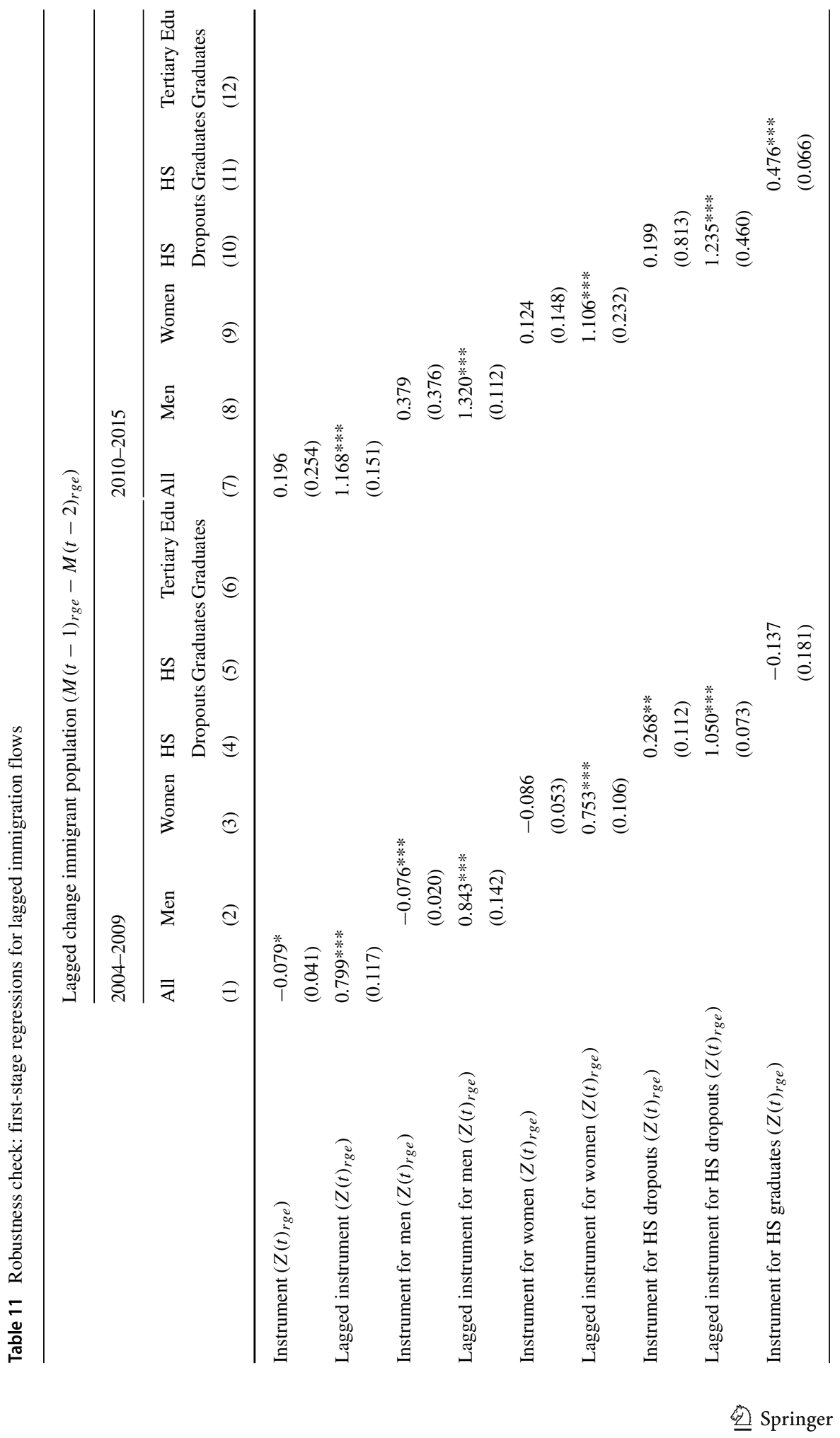




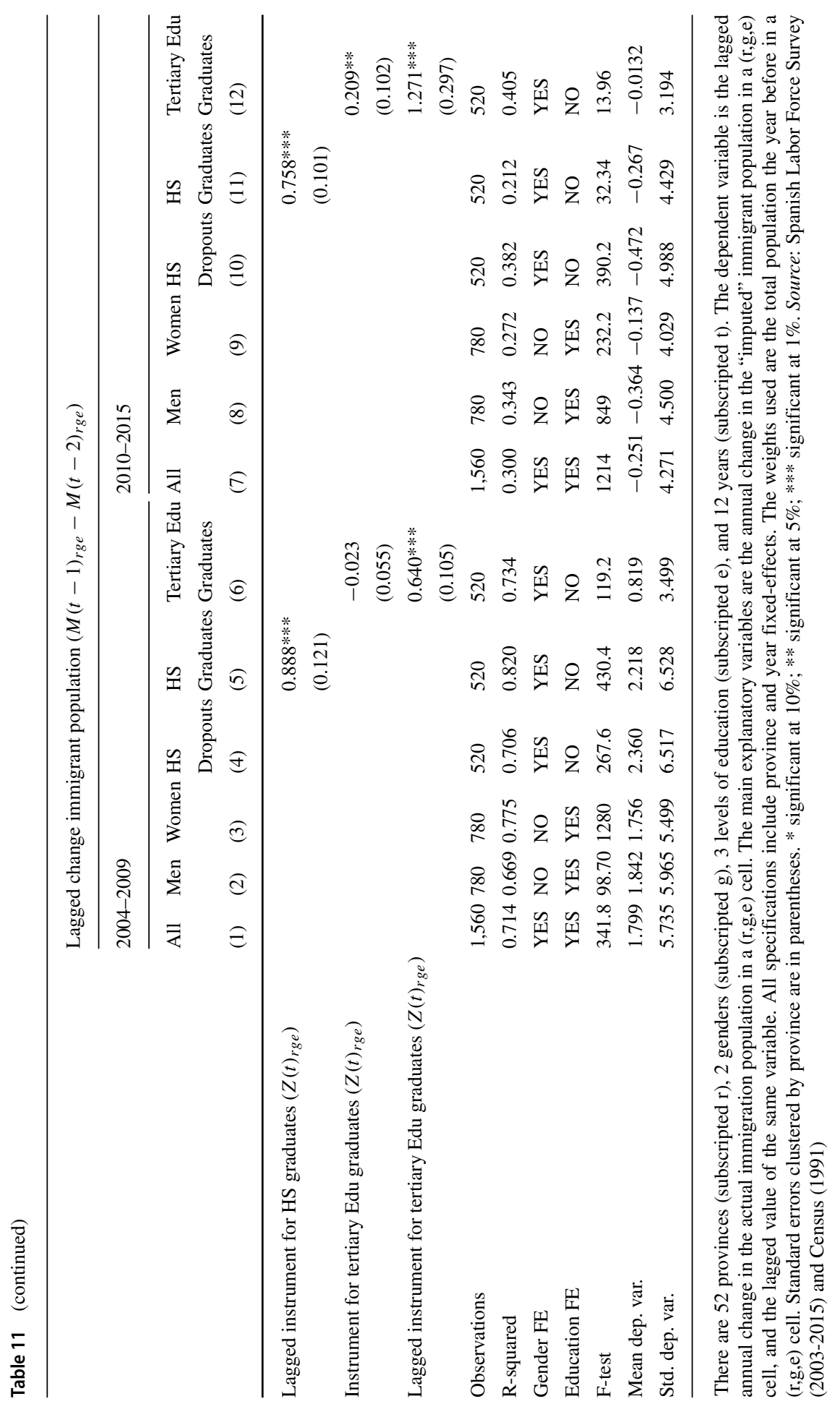


Table 12 Robustness check: workplace accidents of Spanish-born workers

\begin{tabular}{|c|c|c|c|c|c|c|}
\hline & \multicolumn{6}{|c|}{$\begin{array}{l}\text { Change workplace accidents per Spanish-born worker } \\
\left(\frac{W A(t)_{r g}}{E(t)_{r g}}-\frac{W A(t-1)_{r g}}{E(t-1)_{r g}} * 100,000\right)\end{array}$} \\
\hline & \multicolumn{3}{|l|}{ 2004-2009 } & \multicolumn{3}{|c|}{$2010-2015$} \\
\hline & $\begin{array}{l}\text { All } \\
(1)\end{array}$ & $\begin{array}{l}\text { Men } \\
\text { (2) }\end{array}$ & $\begin{array}{l}\text { Women } \\
\text { (3) }\end{array}$ & $\begin{array}{l}\text { All } \\
(4)\end{array}$ & $\begin{array}{l}\text { Men } \\
(5)\end{array}$ & $\begin{array}{l}\text { Women } \\
\text { (6) }\end{array}$ \\
\hline \multicolumn{7}{|l|}{ IV: } \\
\hline Immigrant inflows & $\begin{array}{l}-8.675^{* * *} \\
(1.621)\end{array}$ & & & $\begin{array}{l}0.156 \\
(0.562)\end{array}$ & & \\
\hline Lagged immigrant inflows & $\begin{array}{l}-0.123 \\
(1.381)\end{array}$ & & & $\begin{array}{l}3.370 \text { *** } \\
(0.874)\end{array}$ & & \\
\hline Immigrant inflows of men & & $\begin{array}{l}-11.506 \\
(2.271)\end{array}$ & & & $\begin{array}{l}-1.042 \\
(2.122)\end{array}$ & \\
\hline Lagged immigrant inflows of men & & $\begin{array}{l}0.216 \\
(2.489)\end{array}$ & & & $\begin{array}{l}0.601 \\
(1.027)\end{array}$ & \\
\hline Immigrant inflows of women & & & $\begin{array}{l}-3.604 * * \\
(1.624)\end{array}$ & & & $\begin{array}{l}-1.356 \\
(0.865)\end{array}$ \\
\hline Lagged immigrant inflows of women & & & $\begin{array}{l}0.126 \\
(3.644)\end{array}$ & & & $\begin{array}{l}-0.533 \\
(0.780)\end{array}$ \\
\hline Observations & 1,560 & 780 & 780 & 1,560 & 780 & 780 \\
\hline R-squared & 0.400 & 0.492 & 0.278 & 0.653 & 0.746 & 0.686 \\
\hline Gender FE & YES & NO & NO & YES & NO & $\mathrm{NO}$ \\
\hline First-stage F & 14.52 & 7.386 & 33.47 & 14.71 & 7.265 & 10.97 \\
\hline Kleibergen-Paap LM statistic & 3.561 & 3.420 & 3.718 & 1.590 & 1.396 & 1.639 \\
\hline Mean dep. var. & -57.62 & -113.1 & -2.130 & -59.37 & -101.7 & -17 \\
\hline Std. dep. var. & 704.4 & 873.4 & 473.1 & 371.7 & 456 & 254.8 \\
\hline
\end{tabular}

There are 52 provinces (subscripted r), 2 genders (subscripted g), 3 levels of education (subscripted e), and 12 years (subscripted t). The dependent variable is the annual change in the number of workplace accidents per 100,000 Spanish-born workers in a $(\mathrm{r}, \mathrm{g})$ cell. The main explanatory variables are the annual change in the "imputed" immigrant population in a (r,g,e) cell, and the lagged value of the same variable. All specifications include province, year, and education fixed-effects. The weights used are the number of native employees in a $(\mathrm{r}, \mathrm{g})$ cell. Standard errors clustered by province are in parentheses. * significant at $10 \%$; ** significant at 5\%; $* * *$ significant at 1\%. Source: Spanish Labor Force Survey (2003-2015) and Census (1991) 
Table 13 Robustness check: heterogeneity in the effects on the workplace accidents of spanish-born workers

\begin{tabular}{|c|c|c|c|c|}
\hline \multicolumn{5}{|c|}{$\begin{array}{l}\text { Change workplace accidents per Spanish } \\
\left(\frac{W A(t)_{r g}}{E(t)_{r g}}-\frac{W A(t-1)_{r g}}{E(t-1)_{r g}} * 100,000\right)\end{array}$} \\
\hline \multicolumn{3}{|c|}{ 2004-2009 } & \multicolumn{2}{|c|}{ 2010-2015 } \\
\hline Mild & Severe & Services & Mild & Construction \\
\hline (1) & (2) & (3) & (4) & (5) \\
\hline
\end{tabular}

\begin{tabular}{llllll} 
IV: & & & & \\
Immigrant inflows & $-8.391 * * *$ & $-0.284 * * *$ & $-7.096 * *$ & 1.084 & $25.652 * * *$ \\
& $(1.663)$ & $(0.082)$ & $(3.604)$ & $(0.799)$ & $(7.453)$ \\
Lagged immigrant inflows & -0.123 & -0.000 & 1.090 & $5.347 * * *$ & $23.577 * * *$ \\
& $(1.332)$ & $(0.078)$ & $(0.903)$ & $(1.060)$ & $(4.913)$ \\
Observations & 1,560 & 1,560 & 1,560 & 1,872 & 1,872 \\
R-squared & 0.402 & 0.186 & 0.222 & 0.604 & 0.193 \\
First-stage F & 14.52 & 14.52 & 16.88 & 11.81 & 10.27 \\
Kleibergen-Paap LM statistic & 3.561 & 3.561 & 3.667 & 1.503 & 1.558 \\
Mean dep. var. & -53.12 & -4.497 & 44.87 & -80.01 & -217.8 \\
Std. dep. var. & 696.9 & 16.79 & 487.3 & 360.7 & 2714 \\
\hline
\end{tabular}

There are 52 provinces (subscripted r), 2 genders (subscripted g), 3 levels of education (subscripted e), 12 years (subscripted t), 4 economic activities (subscripted a), and 2 levels of severity (subscripted s). The dependent variables are: $(1-2,4)$ the annual change in the number of workplace accidents per 100,000 Spanish-born workers in a $(\mathrm{r}, \mathrm{g}, \mathrm{s})$ cell, or $(3,5)$ the annual change in the number of workplace accidents per 100,000 Spanish-born workers in a $(\mathrm{r}, \mathrm{g}, \mathrm{a})$ cell. The main explanatory variables are the annual change in the "imputed" immigrant population in a (r,g,e) cell, and the lagged value of the same variable. All specifications include province, year, gender, and education fixed-effects. The weights used are the number of native employees in a $(\mathrm{r}, \mathrm{g})$ cell. Standard errors clustered by province are in parentheses. ${ }^{*}$ significant at 10\%; ** significant at 5\%; *** significant at 1\%. Source: Spanish Labor Force Survey (2003-2015) and Census (1991) 


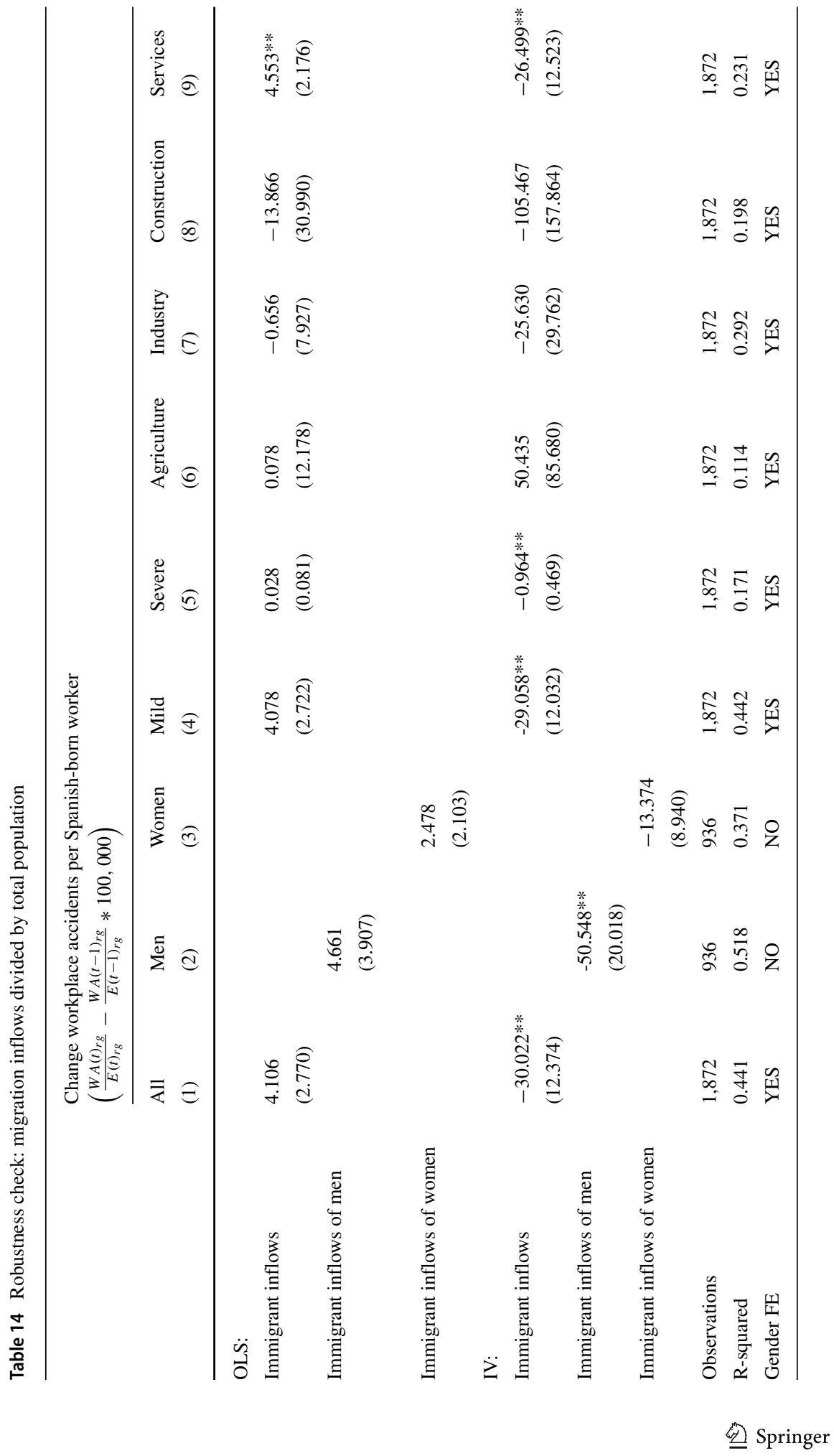




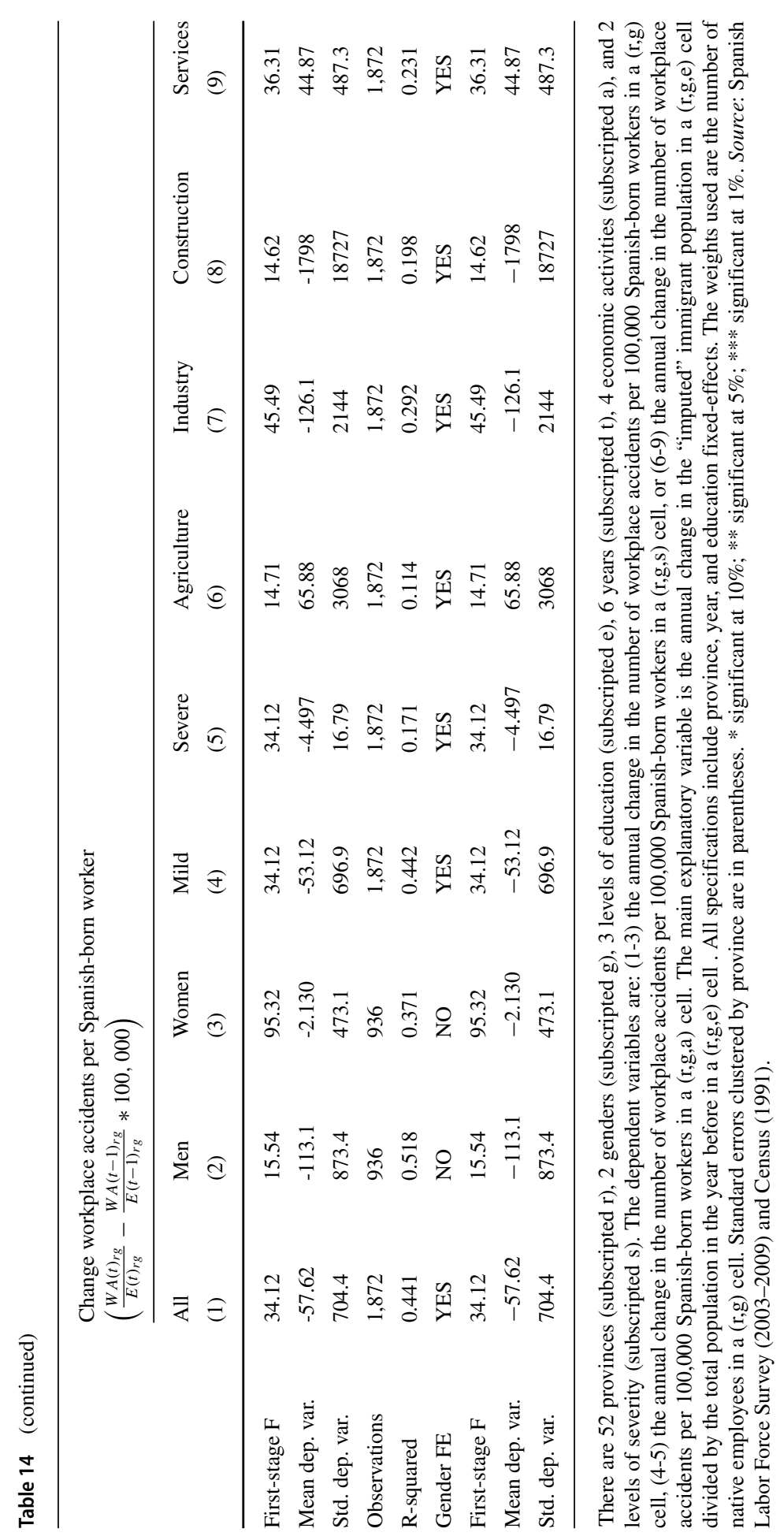


Table 15 Workplace accidents of Spanish-born workers (data collapsed by year, and province level)

Change workplace accidents per Spanish-born worker

$\left(\frac{W A(t)_{r}}{E(t)_{r}}-\frac{W A(t-1)_{r}}{E(t-1)_{r}} * 100,000\right)$

2004-2009

2010-2015

(1)

(2)

OLS:

Immigrant inflows

$-1.518^{* * * *}$

$2.764 * * *$

(0.566)

(0.770)

IV:

Immigrant inflows

$-2.265^{* * *}$

0.754

(0.400)

(0.935)

Observations

312

312

R-squared

0.592

0.772

First-stage F

235.1

18.10

Mean dep. var.

$-91.41$

$-92.36$

Std. dep. var.

678.2

325.2

There are 52 provinces (subscripted $r$ ), and 6 years (subscripted t). The dependent variable is the annual change in the number of workplace accidents per 100,000 Spanish-born workers in a (r) cell. The main explanatory variable is the annual change in the "imputed" immigrant population in a (r) cell. All specifications include province, and year fixed-effects. The weights used are the number of native employees in a (r) cell. Standard errors clustered by province are in parentheses. * significant at $10 \%$; ** significant at 5\%; *** significant at 1\%. Source: Spanish Labor Force Survey (2003-2009) and Census (1991) 

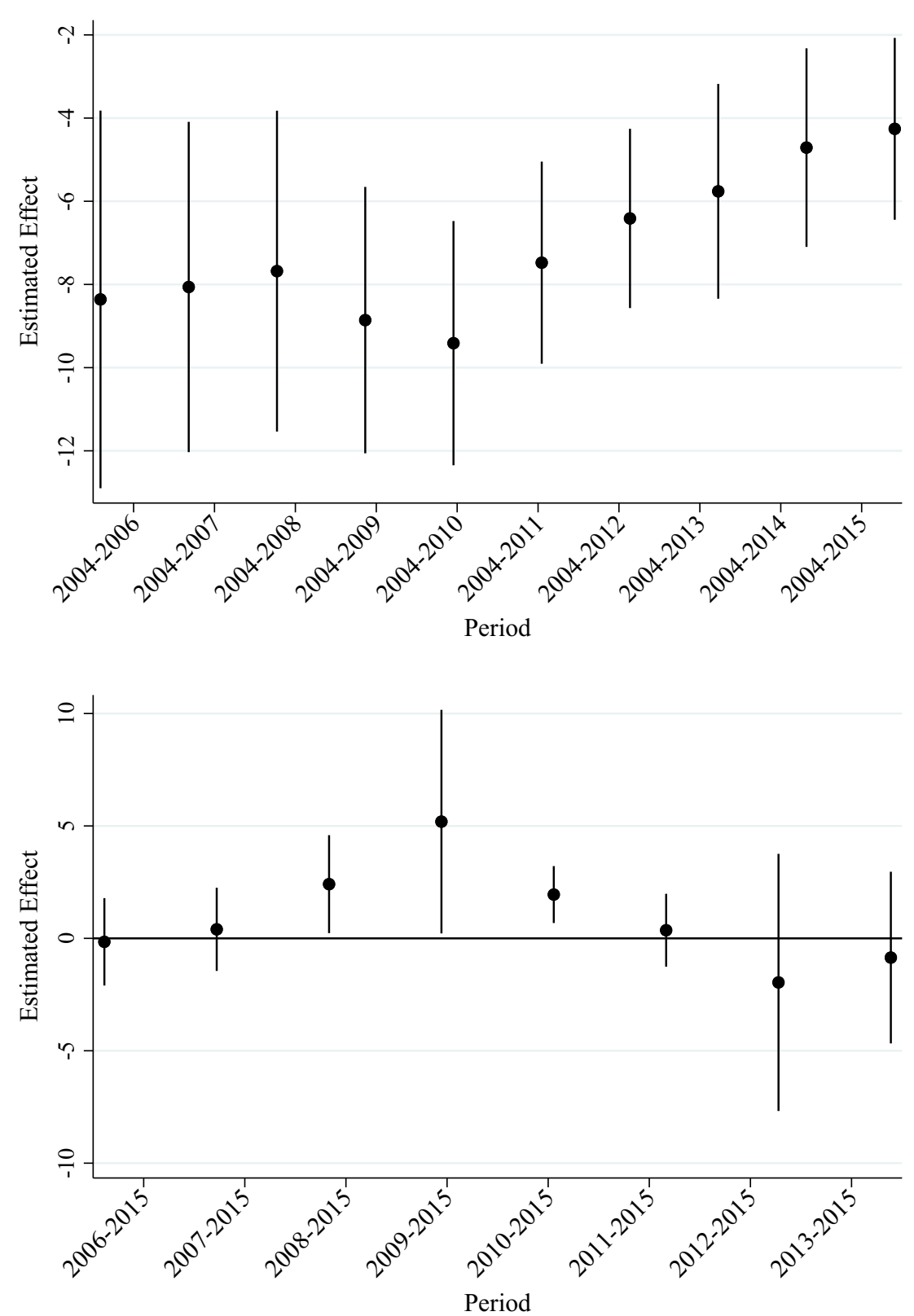

Fig. 9 Effect on workplace accidents of Spanish-born workers in different periods. These graphs represent the estimated coefficient and the $95 \%$ interval of different IV regressions considering different time periods. For all regressions, the dependent variable is the annual change in the number of workplace accidents per 100,000 Spanish-born workers in a (r,g) cell. The main explanatory variable is the annual change in the "imputed" immigrant population in a $(\mathrm{r}, \mathrm{g}, \mathrm{e})$ cell. And the regressions include province, year, gender, and education fixed-effects. The weights used are the number of native employees in a (r,g) cell. Standard errors are clustered at the province level. Source: Register of Workplace Accidents (2003-2015), Spanish Labor Force Survey (2003-2015) and Census (1991) 
Table 16 Workplace accidents of Spanish-born workers (data collapsed by year, province, and gender level)

Change workplace accidents per Spanish-born worker

$\left(\frac{W A(t)_{r g}}{E(t)_{r g}}-\frac{W A(t-1)_{r g}}{E(t-1)_{r g}} * 100,000\right)$

2004-2009 2010-2015

\begin{tabular}{|c|c|c|c|c|c|}
\hline All & Men & Women & All & Men & Women \\
\hline (1) & (2) & (3) & (4) & (5) & (6) \\
\hline
\end{tabular}

OLS:

Immigrant inflows

$-1.754^{* *}$

$5.631 * * *$

(0.864)

(1.552)

Immigrant inflows of men

$$
\begin{aligned}
& -3.414^{* *} \\
& (1.568)
\end{aligned}
$$$$
9.302 * * *
$$

Immigrant inflows of women

$$
\begin{aligned}
& -0.693 \\
& (0.681)
\end{aligned}
$$

IV:

$\begin{array}{ll}\text { Immigrant inflows } & -4.255^{* * *} \\ & (0.846)\end{array}$

Immigrant inflows of men

$-6.906^{* * * *}$
$(1.471)$

\begin{tabular}{|c|c|c|c|c|c|}
\hline & & \multicolumn{3}{|c|}{$-2.047 * * *$} & \multirow{2}{*}{$\begin{array}{l}-0.424 \\
(0.655)\end{array}$} \\
\hline & & $(0.680)$ & & & \\
\hline 1,872 & 936 & 936 & 1,872 & 936 & 936 \\
\hline 0.490 & 0.611 & 0.400 & 0.632 & 0.726 & 0.628 \\
\hline YES & $\mathrm{NO}$ & NO & YES & $\mathrm{NO}$ & $\mathrm{NO}$ \\
\hline 373.5 & 425.7 & 199.6 & 55.84 & 30.37 & 29.11 \\
\hline-57.62 & -113.1 & -2.130 & -81.27 & -127 & -35.56 \\
\hline 704.8 & 874.4 & 473.6 & 363.6 & 446.2 & 248.1 \\
\hline
\end{tabular}

Immigrant inflows of women

There are 52 provinces (subscripted r), 2 genders (subscripted g), and 12 years (subscripted t). The dependent variable is the annual change in the number of workplace accidents per 100,000 Spanish-born workers in a $(\mathrm{r}, \mathrm{g})$ cell. The main explanatory variable is the annual change in the "imputed" immigrant population in a (r, g) cell. All specifications include province, and year fixed-effects. The weights used are the number of native employees in a $(\mathrm{r}, \mathrm{g})$ cell. Standard errors clustered by province are in parentheses. * significant at 10\%; ** significant at 5\%; *** significant at 1\%. Source: Register of workplace accidents (2003-2015), Spanish Labor Force Survey (2003-2015), and Census (1991) 
Table 17 Workplace accidents of Spanish-born workers (data collapsed by year, province and level of severity)

Change workplace accidents per Spanish-born worker

$$
\left(\frac{W A(t)_{r s}}{E(t)_{r}}-\frac{W A(t-1)_{r s}}{E(t-1)_{r}} * 100,000\right)
$$

2004-2009 2010-2015

\begin{tabular}{|c|c|c|c|c|c|}
\hline All & Mild & Severe & All & Mild & Severe \\
\hline (1) & (2) & (3) & (4) & (5) & (6) \\
\hline
\end{tabular}

\section{OLS:}

$\begin{array}{lllllll}\text { Immigrant inflows } & -0.759^{* * *} & -1.463^{* *} & -0.055^{* * *} & 1.382^{* * *} & 2.729 * * * & 0.036 \\ & (0.268) & (0.556) & (0.015) & (0.365) & (0.742) & (0.035) \\ \text { IV: } & & & & & & \\ \text { Immigrant inflows } & -1.132^{* * *} & -2.194 * * * & -0.071 * * * & 0.377 & 0.748 & 0.006 \\ & (0.200) & (0.397) & (0.012) & (0.468) & (0.941) & (0.018) \\ \text { Observations } & 624 & 312 & 312 & 624 & 312 & 312 \\ \text { R-squared } & 0.317 & 0.591 & 0.372 & 0.426 & 0.773 & 0.095 \\ \text { First-stage F } & 261 & 235.1 & 235.1 & 20.10 & 18.10 & 18.10 \\ \text { Mean dep. var. } & -45.70 & -85.85 & -5.559 & -46.18 & -90.85 & -1.503 \\ \text { Std. dep. var. } & 476 & 671.1 & 14.27 & 232.7 & 323.1 & 9.675\end{array}$

There are 52 provinces (subscripted r), 12 years (subscripted t), and 2 levels of severity (subscripted s). The dependent variable is the annual change in the number of workplace accidents per 100,000 Spanishborn workers in a $(\mathrm{r}, \mathrm{s})$ cell. The main explanatory variable is the annual change in the "imputed" immigrant population in a (r) cell. All specifications include province, and year fixed-effects. The weights used are the number of native employees in a $(r)$ cell. Standard errors clustered by province are in parentheses. * significant at $10 \%$; ** significant at 5\%; *** significant at 1\%. Source: Register of Workplace Accidents (2003-2015), Spanish Labor Force Survey (2003-2015), and Census (1991) 


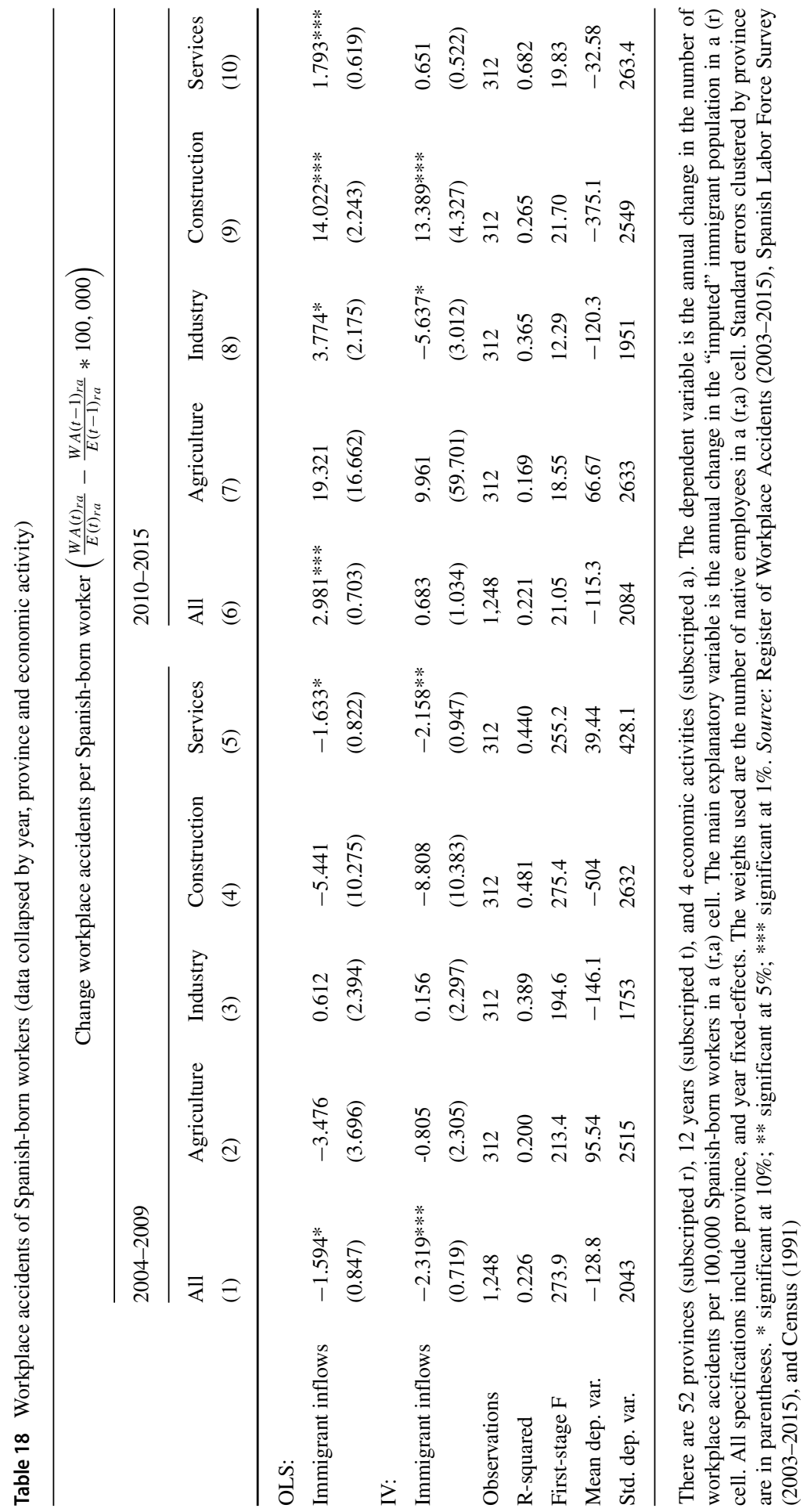



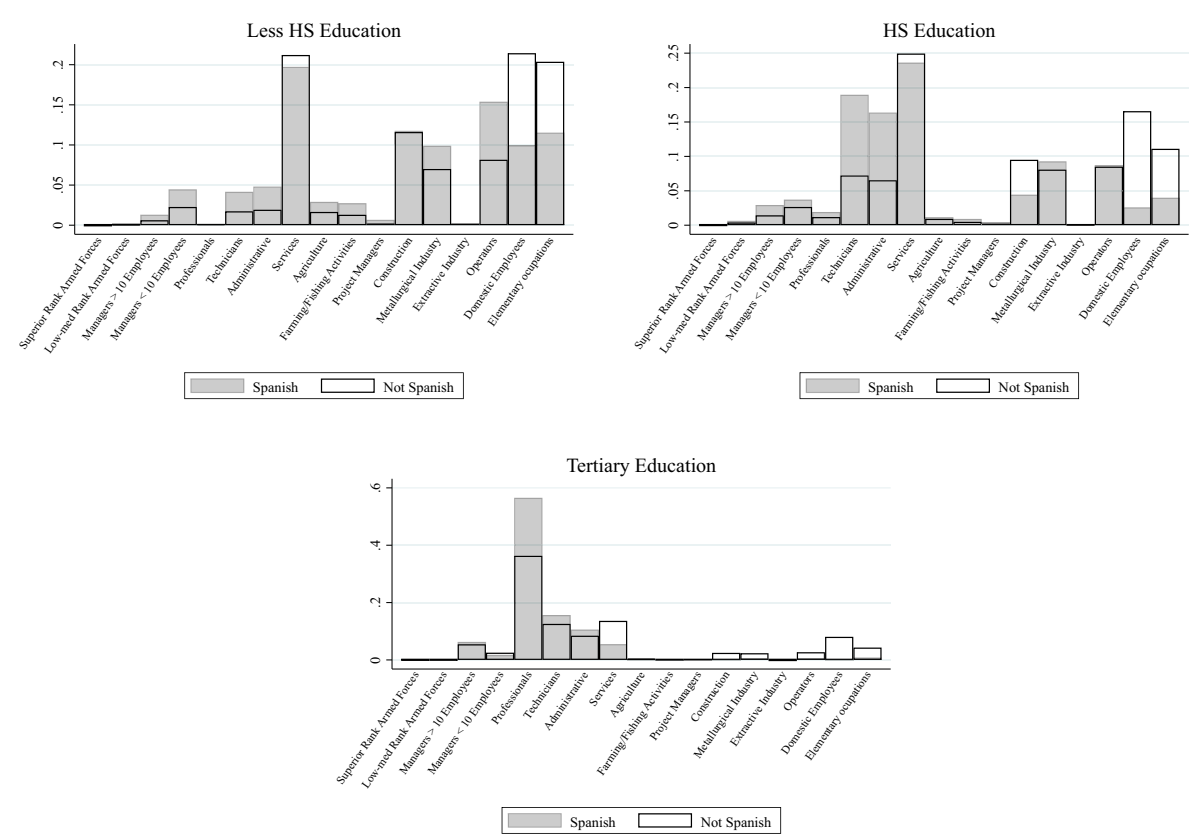

Fig. 10 Occupational distribution by education and nationality. This figure shows the distribution of natives and immigrants in the different occupations by level of education. Source: Spanish Labor Force Survey (2003-2009)

\section{References}

Aibar MMT (2006) Evolución de los accidentes de trabajo entre 1996 y 2003: según los datos de Eurostat en la Europa de los 15 y en España. Prevención, trabajo y salud: Revista del Instituto Nacional de Seguridad e Higiene en el Trabajo 37:25-34

Alacevich C, Nicodemo C (2019) Immigration and work-related injuries: evidence from italian administrative data, IZA discussion paper series,. No. 12510

Alonso X, Pajares M, Recolons L (2015) Inmigración y crisis en españa. Fundació Migrastudium, 5(2):171

Altonji JG, Card D (1991) The effects of immigration on the labor market outcomes of less-skilled natives, in Immigration, trade, and the labor market. University of Chicago Press, Chicago, pp 201-234

Amuedo-Dorantes C, Borra C (2013) On the differential impact of the recent economic downturn on work safety by nativity: the Spanish experience. IZA J Migr 2(1):4

Amuedo-Dorantes C, De la Rica S (2007) Labour market assimilation of recent immigrants in Spain. Br J Ind Relat 45(2):257-284

Amuedo-Dorantes C, De la Rica S (2008) Does immigration raise natives income? National and regional evidence from Spain, IZA Discussion paper series, No. 3486

Antecol Heather, Bedard Kelly (2006) Unhealthy assimilation: why do immigrants converge to American health status levels? Demography 43(2):337-360

Bauer TK, Million A, Rotte R, Zimmermann KF (1998) Immigration labor and workplace safety, IZA Discussion paper series, No. 16

Bertoli S (2010) Networks, sorting and self-selection of Ecuadorian migrants. Annals of Economics and Statistics/Annales d'É,conomie et de Statistique, pp 261-288

Blanes JV, Requena F, Serrano G et al (2011) Labour market adjustment in the Spanish regions: a first examination to the immigration shock, 1995-2002 Technical Report

Borjas GJ (1987) Self-selection and the earnings of immigrants. Technical Report, National Bureau of Economic Research 
Borjas GeorgeJ (1995) The economic benefits from immigration. J Econ Perspect 9(2):3-22

Card D (2001) Immigrant inflows, native outflows, and the local labor market impacts of higher immigration. J Labor Econ 19(1):22-64

Carrasco R, Jimeno J, Carolina Ortega A (2008) The effect of immigration on the labor market performance of native-born workers: some evidence for Spain. J Popul Econ 21(3):627-648

Dillender M, McInerney M (2020) The role of Mexican immigration to the United States in improved workplace safety for natives from 1980 to 2015. J Health Econ 70(10):2280

Farré L (2016) New evidence on the healthy immigrant effect. J Popul Econ 29(2):365-394

Friedberg R, Hunt J (1995) The impact of immigrants on host country wages, employment and growth. J Econ Perspect 9(2):23-44

Giuntella O (2017) Why does the health of Mexican immigrants deteriorate? New evidence from linked birth records. J Health Econ 54:1-16

Giuntella O, Mazzonna F (2015) Do immigrants improve the health of natives? J Health Econ 43:140-153

Giuntella O, Mazzonna F, Nicodemo C, Vargas-Silva C (2019) Immigration and the reallocation of work health risks. J Popul Econ 32(3):1009-1042

Goldsmith-Pinkham P, Sorkin I, Swift H (2018) Bartik instruments: What, when, why, and how. Technical Report, National Bureau of Economic Research

Gonzalez L, Ortega F (2011) How do very open economies adjust to large immigration flows? Evidence from Spanish regions. Labour Econ 18(1):57-70

Instituto Sindical de Trabajo, Ambiente y Salud Saludlaboral (2006) Diferencias y similitudes entre trabajadores inmigrantes y españoles. Cuantificación y análisis de causas., Technical Report

Jaeger DA, Ruist J, Stuhler J (2018) Shift-share instruments and the impact of immigration. Technical Report, National Bureau of Economic Research

Kennedy S, Kidd MP, McDonald JT, Biddle N (2015) The healthy immigrant effect: patterns and evidence from four countries. J Int Migr Integr 16(2):317-332

Moraga JF-H (2011) New evidence on emigrant selection. Rev Econ Stat 93(1):72-96

Ottaviano GIP, Peri G (2005) Rethinking the gains from immigration: Theory and evidence from the US. Technical Report, National Bureau of Economic Research

Stanek M, Ramos AV (2013) Occupational mobility at migration-evidence from Spain. Sociol Res Online 18(4):1-9

Takala J, Hämäläinen P, Saarela KL, Yun LY, Manickam K, Jin TW, Heng P, Tjong C, Kheng LG, Lim S. et al (2014) Global estimates of the burden of injury and illness at work in 2012. J Occup Environ Hyg 11(5):326-337

Publisher's note Springer Nature remains neutral with regard to jurisdictional claims in published maps and institutional affiliations.

\section{Affiliations}

\section{Cristina Bellés-Obrero ${ }^{1,2} \cdot$ Nicolau Martin Bassols ${ }^{2,3} \cdot$ Judit Vall Castello $0^{2,4}$}

Nicolau Martin Bassols

nicolau.martinbassols@monash.edu

Judit Vall Castello

judit.vall@ub.edu

1 Department of Economics, University of Mannheim, Office 326, L7, 3-5, 68161, Mannheim, Germany

2 CRES-UPF, Barcelona, Spain

3 Center for Health Economics, Monash University, 15 Innovation Walk, VIC, 3800, Clayton, Australia

4 Department of Economics and Institut d'Economia de Barcelona, Universitat de Barcelona, John M.Keynes, 1-11, 08034, Barcelona, Spain 